\title{
多孔碳纳米材料构建抗肿瘤药物靶向传递系统的研究进展
}

\author{
程晓昆 ${ }^{1,2}$, 张 越 ${ }^{1}$, 吕海军 ${ }^{1}$, 刘歆颖 ${ }^{2}$, 侯森林 ${ }^{3}$, 陈爱兵 ${ }^{1}$
}

(1. 河北科技大学 化学与制药工程学院, 石家庄 $050018 ; 2$. 南非大学 非洲可持续性能源发展研究所, 约翰内斯堡 1710 , 南非; 3. 河北医科大学第二附属医院 胆胰内镜外科, 石家庄 050000)

摘 要: 抗肿瘤药物靶向传递系统是提高传统化疗药物疗效, 并降低其毒副作用的重要手段。以多孔碳纳米材料为 药物载体, 根据肿瘤组织微环境特点, 构建抗肿瘤药物靶向传递系统是实现靶向治疗方案的有效方式。本文围绕基 于多孔碳纳米材料的抗肿瘤药物靶向传递系统的构建及应用进行综述, 描述了多孔碳纳米材料适宜载药的设计、合 成及功能化修饰; 通过理论与实例相结合的方式, 介绍了提高多孔碳纳米材料载药量和实现联合给药的有效策略; 从内源和外源性敏感刺激的角度, 重点分析了多孔碳纳米材料基于肿瘤微环境构建的靶向传递系统的机制和应用; 阐述了多孔碳纳米材料作为抗肿瘤药物载体面临的生物相容性和生物降解性的问题, 并分析了可能的解决途径; 展望了多孔碳纳米材料在构建肿瘤药物靶向传递系统应用中的前景及发展方向, 为研发靶向、可控的抗肿瘤药物传 递系统提供了理论依据和例证支持。

关 键 词: 多孔碳纳米材料; 结构设计; 抗肿瘤; 靶向; 药物传递系统; 综述 中图分类号: TQ174 文献标识码: A

\section{Porous Carbon Nanomaterials Based Tumor Targeting Drug Delivery System: a Review}

\author{
CHENG Xiaokun ${ }^{1,2}$, ZHANG Yue ${ }^{1}$, LÜ Haijun ${ }^{1}$, LIU Xinying ${ }^{2}$, HOU Senlin ${ }^{3}$, CHEN Aibing $^{1}$
}

(1. College of Chemical and Pharmaceutical Engineering, Hebei University of Science and Technology, Shijiazhuang 050018, China; 2. Institute for the Development of Energy for African Sustainability, University of South Africa, Johannesburg 1710, South Africa; 3. Bilio-Pancreatic Endoscopic Surgery Department, The Second Hospital of Hebei Medical University, Shijiazhuang 050000, China)

\begin{abstract}
Chemotherapy is the main method used for cancer treatment. However, most chemotherapeutic drugs show low selectivity towards tumor cells. When killing tumor cells, chemotherapeutic drugs can also damage normal tissue cells and induce a series of side effects and toxic reactions, such as gastrointestinal reactions, calvities and so on. An effective way to reduce the adverse drug reactions is to construct targeted delivery systems based on the microenvironment properties of tumor tissue. Porous carbon nanomaterials (PCN), with excellent properties such as good structural stability, pores, and easily modified surface, are promising candidate to be used for such strategy. In this paper, the construction and application of the PCN-based targeted antitumor drugs delivery system were reviewed; the structural properties, the design philosophy of PCN suitable for drug loading were summarized; the effective
\end{abstract}

收稿日期：2020-05-06; 收到修改稿日期：2020-06-04; 网络出版日期：2020-07-13

基金项目: 国家自然科学基金(21676070); 河北省高校百名优秀创新人才支持计划项目(SLRC2017034); 北京分子科学国 家实验室项目

National Natural Science Foundation of China (21676070); Hebei One Hundred-Excellent Innovative Talent Program (III) (SLRC2017034); Beijing National Laboratory for Molecular Sciences

作者简介: 程晓昆(1985-), 女, 博士研究生. E-mail: kunkuner007@163.com CHENG Xiaokun (1985-), female, PhD candidate. E-mail: kunkuner007@163.com

通信作者：陈爱兵，教授.E-mail: chen_ab@163.com CHEN Aibing, professor. E-mail: chen_ab@163.com 
strategies to improve drug loading on PCN for combined drug delivery were discussed both theoretically and experimentally. The mechanism and applications of PCN for tumor microenvironment based targeted delivery system were analyzed from the perspectives of endogenous sensitive stimulations (such as acidity, redox potential and specific enzyme), exogenous sensitive stimulations (such as light and magnetic) and multiple sensitive stimulations (such as double sensitive stimulations, including acidity/redox potential, acidity/magnetic and magnetic/light, and three sensitive stimulation, including acidity/redox potential/light). The biocompatibility and biodegradability of PCN used as anti-tumor drug delivery system was discussed, and the possible solutions were analyzed. The prospects of the application of PCN to be used in tumor drugs were discussed at the end of this review. This review provides theoretical basis and examples towards design and synthesis of porous carbon (PC) materials based anti-tumor drug delivery system, which may help the research and development of targeted and controllable tumor treatment.

Key words: porous carbon nanomaterials; structural design; antitumor; targeting; drug delivery systems; review

根据世界卫生组织最新发布的全球癌症统计报 告, 2018 年全球因癌症而死亡的人数高达 960 万人, 预计到 2030 年这个数据将会上升至 1300 万人 ${ }^{[1]}$ 。 在我国, 迄今为止, 每年新增癌症患者约 430 万人, 因癌症死亡的约 281 万人 ${ }^{[2]}$, 无论是癌症的发病率, 还是死亡率, 均呈现逐年上升的趋势。由此可见, 恶 性肿瘤已经是严重威胁人类健康的重大疾病之一, 防治形势日益严峻。现阶段, 癌症的治疗主要依靠 化学疗法 ${ }^{[3]}$, 然而, 现有的化疗药物虽然可以有效 杀灭恶性肿瘤 ${ }^{[4]}$, 却存在附带杀伤正常细胞、损害正 常生理机能、促使肿瘤细胞对化疗药物产生抗药性 以及引起严重毒副作用等缺点 ${ }^{[5]}$, 导致应用受限。将 适量的化疗药物选择性地传递到肿瘤部位, 实现可 控释放是克服上述缺点的重要手段, 但传统的药物 制剂在体内分布具有非选择性, 难以将抗肿瘤药物 有效地传送到肿瘤细胞内部, 且停留时间较短, 严 重影响药物的有效性 ${ }^{[6]}$ 。通过选择合适的药物载体, 并基于肿瘤组织独特的微环境进行设计, 构建不同 敏感特性的抗肿瘤药物靶向传递系统, 是实现药物 有效、可控发挥作用的解决方案之一 ${ }^{[7-8]}$ 。

近年来, 碳纳米材料在靶向药物传递领域中的 应用受到了国内外科研工作者们的密切关注, 诸如 富勒烯、碳纳米管、石墨烯及氧化石墨烯等均已在 药物传递领域获得了一些积极进展 ${ }^{[9-13]}$, 但这些碳 纳米材料均具有一定的生物毒性 ${ }^{[14-17]}$, 长期使用会 对人体健康带来潜在危害。多孔碳纳米材料由于具 有较好的生物相容性 ${ }^{[18-19]}$, 可有效地避免对正常细 胞和非肿瘤组织产生额外的毒副作用, 在抗肿瘤药 物靶向传递领域展现出了独特的发展潜力和应用 价值。

本文以多孔碳纳米材料的结构特征为切入点, 通过多种对肿瘤微环境特性敏感的物理化学因素敏
感机制和研究实例的分析, 以理论和实例相结合的 方式对适宜构建抗肿瘤药物传递系统的多孔碳纳米 材料设计合成及其应用进展进行了综述, 并提出了 目前仍存在的问题，展望了其未来的发展方向。

\section{1 适宜载药的多孔碳纳米材料设计合 成与功能化修饰}

多孔碳纳米材料不仅具有酸碱体系中结构稳 定、比表面积大和生物相容性良好等结构特征, 还 存在可与药物分子形成超分子 $\pi-\pi$ 堆叠作用、制备 方法丰富多样和易于功能化修饰等特性 ${ }^{[20-21]}$, 为其 应用于构建抗肿瘤药物靶向传递系统提供了良好的 基础。

\section{1 多孔碳纳米材料适宜载药的优势结构 特征}

构建优异的抗肿瘤药物载体的主要目的是将足 量药物定向传输到肿瘤部位, 并实现可控释放 ${ }^{[22]}$ 。 多孔碳纳米材料具备如下结构优势 ${ }^{[23-25]}$ : (1)多孔碳 纳米材料的碳质结构不易与酸碱发生反应, 表现出 良好的结构稳定性, 可作为药物分子的优良载体。 同时, 利用载体的屏蔽作用可保护负载的药物分子 在传输过程中不受酸碱介质的影响, 控制药物分子 不过早释放, 使其能够完整到达肿瘤组织。(2)多孔 碳纳米材料具有丰富的孔道结构, 以及较大的比表 面积, 为药物分子提供了充足的结合或吸附位点, 可在有限的存储体积中实现高效负载, 并为药物分 子的运输、扩散提供了传递通道。(3)多孔碳纳米材 料的碳质骨架可通过特殊的超分子 $\pi-\pi$ 堆叠作用和 共价键作用与药物分子相结合, 有效提高药物分子 的负载量, 另外, 超分子 $\pi-\pi$ 堆叠作用易对外部触 
发如酸度、温度等刺激敏感，可构建具有不同功能 和协同作用的药物传递系统。(4)多孔碳纳米材料较 容易通过共价及非共价修饰的手段进行表面改性, 有助于与具有刺激响应性的纳米粒子结合, 利用环 境敏感因素驱动药物在细胞内释放, 提高对肿瘤微 环境或靶标的特异性识别, 可较好地控制药物扩散 动力学。

多孔碳纳米材料适宜载药的主要决定因素是较 大的比表面积和孔容、丰富的多孔、易于与靶向配 体结合以及易于在细胞内发挥作用。根据报道, 跨 膜传递载体的最佳尺寸应小于 $100 \mathrm{~nm}^{[26]}$, 另外, 载 体材料的良好分散性决定了药物在体内循环传输过 程中的流动性。因此, 在设计适于载药的多孔碳纳 米材料时, 在粒径上应小于 $100 \mathrm{~nm}$; 在分散形态上 应具有良好的单分散性; 在结构上应以类球型 ${ }^{[27]}$ 、 具有中大孔或者大体积空腔的结构。

\section{2 多孔碳纳米材料设计合成}

多孔碳纳米材料的设计合成是构建抗肿瘤药物 载体的关键步骤。近年来, 多孔碳纳米材料不断被 优化创新，发展了多种合成方法(表 1)。理论上，可 通过多孔碳纳米材料制备方法中的一种或多种组合, 借助模板法、直接热解或化学气相沉积等手段, 获 得可控的多孔碳结构, 从而设计出具有理想形态、 尺寸、孔隙率和化学组成的载体材料 ${ }^{[28]}$ 。

\subsection{1 模板法}

模板法是获得具有规则孔结构和孔径分布的多 孔碳纳米材料最成熟的方法之一, 主要分成硬模板 法和软模板法 ${ }^{[41]}$ (图 1)。

硬模板法通常采用刚性结构的材料, 如二氧化 硅、氧化镁、氧化铝和沸石等作为硬模板, 用可交 联的前体填充或涂覆 ${ }^{[22]}$, 经热解处理将前体转化为 均匀规则的碳质结构, 最后将模板蚀刻去除, 获得 多孔碳纳米材料。硬模板法是对各种多孔模板的反 向复制，避免了控制客体物质的水解和缩合以及 它们与表面活性剂的组装, 并确保完全填充中间 通道, 因此可以合成各种多孔结构 ${ }^{[43]}$ 。但可供使用 的硬模板较少, 制备成本相对较高, 耗时较长 ${ }^{[44]}$, 还需要使用有害化学物质去除模板, 从而限制了 其广泛应用 ${ }^{[45]}$ 。

软模板法主要采用可热分解的表面活性剂, 如阴离子和阳离子表面活性剂或非离子型表面活 性剂用作软模板，与碳前体和溶剂分子(水或乙醇) 共同组成圆柱或球形胶束, 通过水热处理、协同组 装或蒸发诱导自组装等策略, 得到多孔碳纳米材 料。离子型表面活性剂热分解产生微孔或小的介孔 (2 4 $\mathrm{nm}$ ), 非离子表面活性剂还可以产生超过 $10 \mathrm{~nm}$ 的介孔 ${ }^{[46]}$ 。相较于硬模板法而言, 软模板法 不需要提前合成模板，操作工艺更简单，成本更低

表 1 多孔碳纳米材料的制备方法

Table 1 Preparation of porous carbon nanomaterials

\begin{tabular}{llll}
\hline \multicolumn{1}{c}{ Preparation } & \multicolumn{1}{c}{ Basic steps } & Ref. \\
\hline Hard template method & $\begin{array}{l}\text { Impregnate the preformed hard template with carbon source, then remove the } \\
\text { template after pyrolysis at a high temperature }\end{array}$ \\
Soft template method & $\begin{array}{l}\text { Through surfactant assembly, the template is removed after pyrolysis at high } \\
\text { temperature }\end{array}$ & [31-33] \\
Direct pyrolysis method & $\begin{array}{l}\text { Direct pyrolysis of carbon precursors, such as MOF, biomass, ionic liquid or } \\
\text { polymer }\end{array}$ & [34-37] \\
Chemical vapor deposition method & $\begin{array}{l}\text { Introducing two or more gaseous carbon precursors into the tubular quartz } \\
\text { reactor, carbon materials obtained through pyrolysis }\end{array}$ & [38-40] \\
\hline
\end{tabular}

(a)

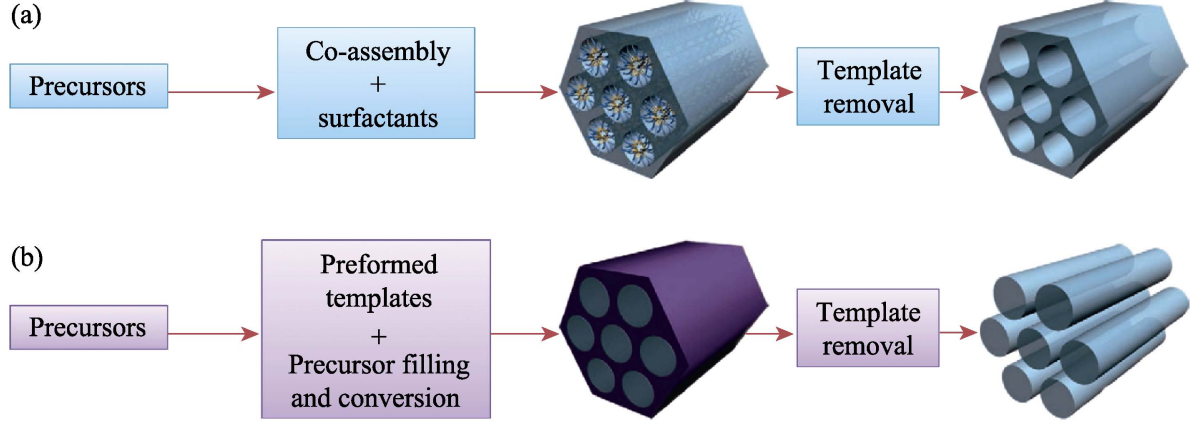

图 1 模板法合成多孔碳纳米材料示意图 ${ }^{[41]}$

Fig. 1 Schematic illustration of template method for synthesis of $\mathrm{PCN}^{[41]}$

(a) Soft template method; (b) Hard template method 
廉，并且制备的多孔碳纳米材料孔径分布更加均匀 有序 ${ }^{[47]}$ 。

\subsection{2 直接热解法}

直接热解法是通过高温处理破坏碳前驱体材料 中的化学键, 实现制备多孔碳纳米材料的过程 ${ }^{[48]}$ 。 常见的碳前驱体包括金属有机骨架化合物、生物质、 聚离子液体和各种有机共聚物等。

金属有机骨架是通过配位键将含金属(如 Co、 $\mathrm{Fe} 、 \mathrm{Zn}$ 等)的无机结构单元与有机配体组装在一起, 融合了配位聚合物以及晶体材料的结构特点 ${ }^{[49]}$, 具 备组成和结构丰富多样 ${ }^{[50]}$ 、较高的比表面积、均匀 的孔径分布和可调的化学结构 ${ }^{[51]}$ 等优势, 合成过程 示意图见图 2(a) ${ }^{[52]}$ 。直接热解炭化金属有机骨架及 其衍生物时，其有机配体在保持多孔骨架的同时转 化为碳，无机结构单元被还原为金属氧化物或金属, 可通过酸蚀去除 ${ }^{[53]}$, 获得具有可调粒径、高比表面 积、较大孔体积和均匀孔结构的多孔碳纳米材 料 ${ }^{[54-55]}$ 。这种制备方法简单, 不需要额外碳源, 但由 于碳骨架的形成温度高于释放分解气体的温度，金
属有机骨架合成成本比较高昂，难以大批量制备 ${ }^{[56]}$ 。

生物质不但具有独特的生物组织自然结构 ${ }^{[47]}$, 而且来源丰富、具有成本效益, 是可直接热解碳化 的典型碳前驱体之一, 合成示意图见图 $2(b)^{[57]}$ 。在 碳化过程中，这些生物组织自然结构一般不会被破 坏，可以制备具有分级多孔结构的多孔碳纳米材 料 ${ }^{[58]}$, 但通常直接热解生物质获得的多孔碳材料比 表面积较低, 空隙不发达, 需要进一步活化 ${ }^{[28]}$ 。

聚离子液体由离子液体单体聚合生成，在重复 单元上具有阴、阳离子基团，兼具离子液体和多聚 物的特点 ${ }^{[59]}$, 由于阴、阳离子之间的静电作用, 致 孔剂均匀地分布在聚合物基质中，使多孔碳纳米材 料的形貌和微观结构易于调控 ${ }^{[32]}$, 可通过不同种 类、不同配比阴离子和阳离子的选择以及调节聚合 方法获得不同性质的多孔碳纳米材料 ${ }^{[53]}$ 。

各种共价有机骨架和共轭共聚物, 如苯胺和吡 咯共聚物、聚酰亚胺以及嵌段共聚物等, 也可用作 碳前驱体, 通过控制热解参数, 如升温速率和热解 时间, 可进行多孔碳纳米材料的结构和表面性质 (a)
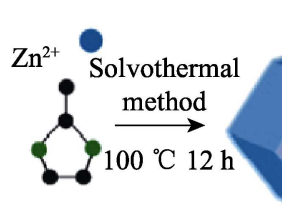

Methylimidazole

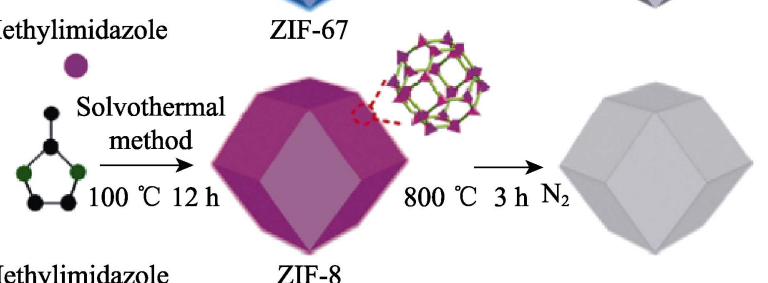

Methylimidazole ZIF-8 (b)

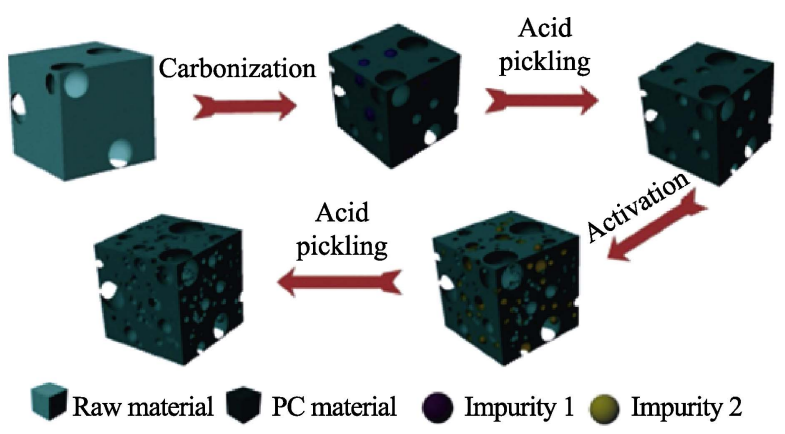

(c)

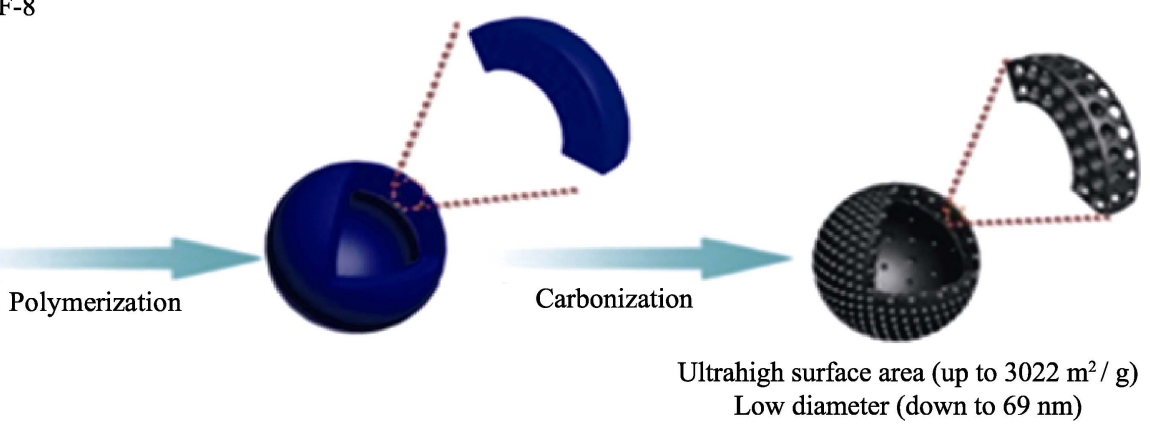

Low diameter (down to $69 \mathrm{~nm}$ )

(d)
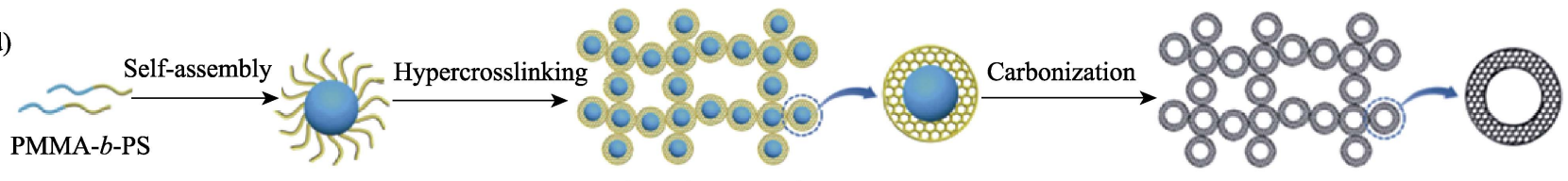

Polymeric nanoscale

图 2 直接热解法制备(a)金属有机骨架热解成碳 ${ }^{[52]},(\mathrm{b})$ 植物组织制备分级多孔碳 ${ }^{[57]}$, (c)苯胺-吡咯共聚物热解成碳 ${ }^{[60]}$,

(d)嵌段共聚物聚甲基丙烯酸甲酯-苯乙烯热解成碳[61]

Fig. 2 Schematic illustration of direct pyrolysis methods for synthesis of porous carbon nanomaterials (PCN)

(a) Preparation of MOF and porous carbon $(\mathrm{PC})^{[58]}$; (b) Preparation of PC from plant tissue ${ }^{[59]}$;

(c) Preparation of PC from PAN-co-PPy ${ }^{[60]}$; (d) Preparation of PC from PMMA-co-PS ${ }^{[61]}$ 
的精细设计, 如图 2(c, d $)^{[60-61]}$ 。

\subsection{3 化学气相沉积法}

化学气相沉积法是一种可将不稳定的碳前驱体 转化成稳定固态碳的合成方法, 具有经济有效、易 于操作、可重复性高, 有利于大量制备等特点。通 常可分为无催化剂的和有催化剂的化学气相沉积 法 ${ }^{[62]}$ 。无催化剂的化学气相沉积法可直接在保护气 (如 $\mathrm{Ar} 、 \mathrm{~N}_{2}$ ) 的氛围中热解含碳的气相有机物, 获得 多孔碳纳米材料。有催化剂的化学气相沉积法是在 保护气的氛围下, 利用含碳前驱体的气体或蒸汽流 经催化剂表面进行催化分解, 从而生成多孔碳纳米 材料, 催化剂通常固定在载体上置于石英反应器内 发挥作用 ${ }^{[63]}$ 。化学气相沉积法制备多孔碳的过程中 影响因素较多, 如温度、碳源的流速和沉积时间等 均会对多孔碳纳米材料的尺寸、形貌和产率造成影 响。另外, 使用含有杂原子的前驱体材料可以得到 不同掺杂的多孔碳纳米材料。

\section{3 多孔碳纳米材料功能化修饰}

多孔碳纳米材料功能化的主要目的是在其表面 进行亲水性修饰，以避开巨噬细胞清除，最大程度 地延长药物循环时间和靶向能力 ${ }^{[64]}$ 。多孔碳纳米材 料的碳质结构具有高度的疏水性, 因此, 在构建药 物传递载体之前须通过共价或非共价作用进行适当 的功能化修饰 ${ }^{[65]}$ 。经过修饰的多孔碳纳米材料不仅 能够被环境敏感因素驱动，增强药物的靶向性、溶 解性和体外稳定性, 同时还具有高渗透、长滞留效 应，更容易实现被肿瘤细胞胞摄入等效果 ${ }^{[66]}$ 。

\subsection{1 共价修饰}

共价修饰通常是在多孔碳纳米材料表面引入羟 基、羧基或氨基等亲水性官能团，用来保护靶向配 体或药物 ${ }^{[67-68]}$ 。如采用硝酸、过硫酸铵/硫酸或双氧 水等氧化剂在多孔碳纳米材料表面均匀地生成羧基 官能团，有利于多孔碳纳米材料与肿瘤细胞完成同 质相互作用 ${ }^{[69-70]}$ 。如图 3 所示, Kapri 等 ${ }^{[71]}$ 采用硝酸

(a)

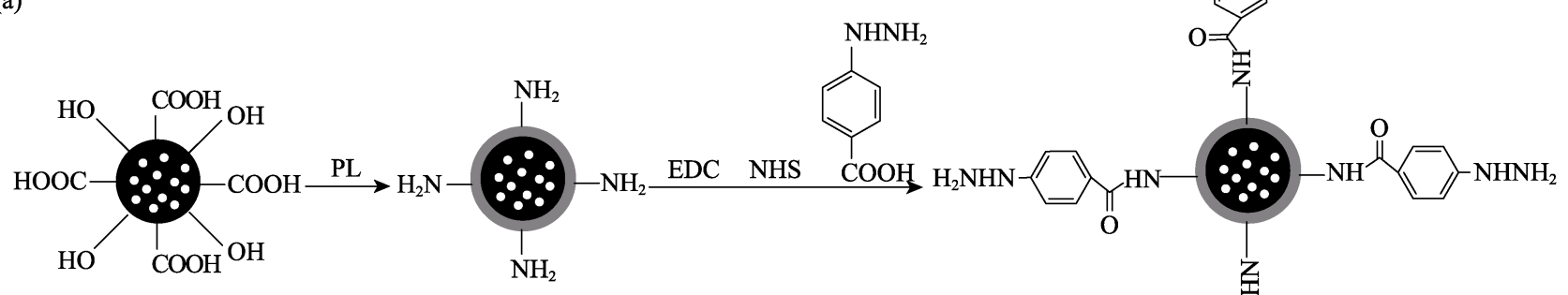

f-PCN

CN-PL

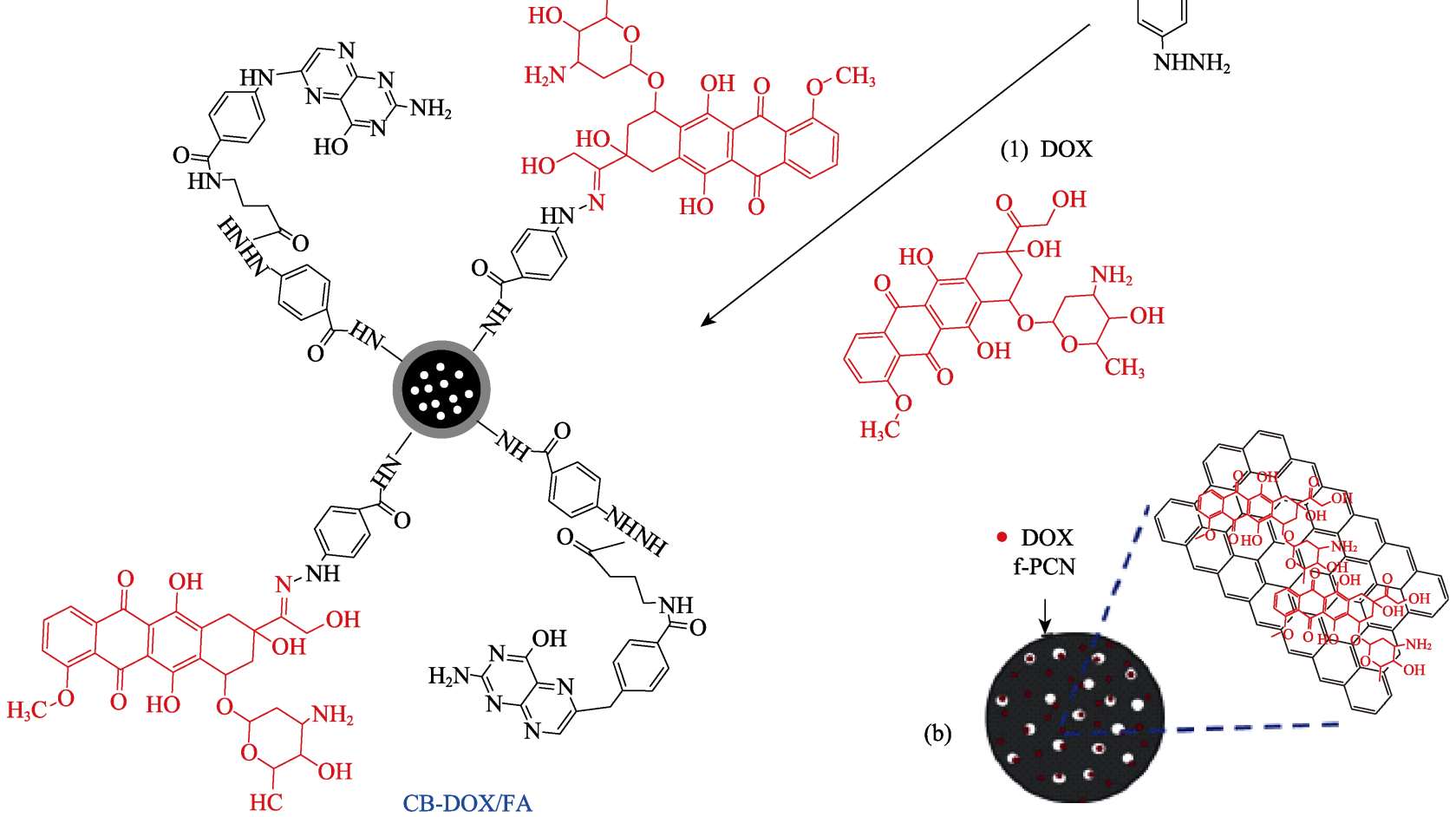

图 3 (a)羧基化的多孔碳球与阿霉素和叶酸偶联的制备, (b)阿霉素在孔道和表面的吸附形式 ${ }^{[71]}$

Fig. 3 (a) Schematic illustration of the preparation of DOX and FA conjugate with f-PCN to form CB-DOX/FA, and (b) the loading of DOX inside the pores and at the surface of functionalized PCN (f-PCN) ${ }^{[71]}$ 
作为氧化剂, 获得了羧基官能化的多孔碳球, 将其 通过 4-苯肼甲酸 $/ N$-(3-二甲氨基丙基)- $N$-乙基酰胺、 $N$-差基琥珀酰胺 $/ N$-(3-二甲氨基丙基)- $N$-乙基酰胺、 叶酸(FA)分别进行功能化修饰后, 进一步装载阿霉 素(DOX), 结果表明, 修饰后的多孔碳球装载的药 物量明显高于简单物理吸附, 并有效防止了药物分 子过早释放, 叶酸 $/ N$-(3-二甲氨基丙基)- $N$-乙基酰胺 修饰后的多孔碳球可进入细胞内部发挥作用。该课 题组在后续的研究中, 采用聚乙烯亚胺和叶酸进行 功能化修饰了将装载阿需素的多孔碳球, 结果表明, 修饰后的多孔碳球对人宫颈癌细胞和乳腺癌细胞均 表现出了良好的治疗效果 ${ }^{[72]}$ 。

\subsection{2 非共价修饰}

在多孔碳纳米材料表面进行非共价修饰的反应 条件相对温和, 主要通过静电力、 $\pi-\pi$ 堆叠作用、氢 键或范德华力等进行 ${ }^{[73]}$ 。如利用 $\pi-\pi$ 堆叠作用可将 肿瘤标志物及其相应的适配体针定在多孔碳纳米材 料表面, 针对目标蛋白质有敏感的响应能力 ${ }^{[45]}$ 。 $\mathrm{Li}$ 等 ${ }^{[74]}$ 基于酞菁类荧光探针 $\mathrm{Cy} 3$ 标记的单链 DNA 与 多孔碳球之间的非共价 $\pi-\pi$ 堆叠作用, 特异性结合 在多种恶性肿瘤中过量表达的细胞表面粘蛋白 1 (MUC1), 用于细胞、组织切片和体内肿瘤等的癌症 成像，可清晰地分辨肿瘤与正常组织之间的区别。 同时，通过该作用力还可以制备特异性酶识别的抗 肿瘤药物传递系统 ${ }^{[75]}$, 如图 4 所示。

\section{2 基于多孔碳纳米材料的抗肿瘤药物 靶向传递系统的构建}

理想的药物传递载体应具有以下特征 ${ }^{[76-77]}$ : 具 有可控的粒径、孔容和药物分子负载能力; 可避免 对正常细胞和组织产生多余的毒副作用; 可设计特 定的释放时间，以响应内源性或外源性刺激; 具有 对肿瘤微环境的高度选择性和对肿瘤靶细胞的特异 性识别功能。多孔碳纳米材料不仅具有较高的药物 负载量, 还可以实现对肿瘤微环境的多重刺激响应, 且具有良好的生物相容性, 是具有发展潜力的抗肿

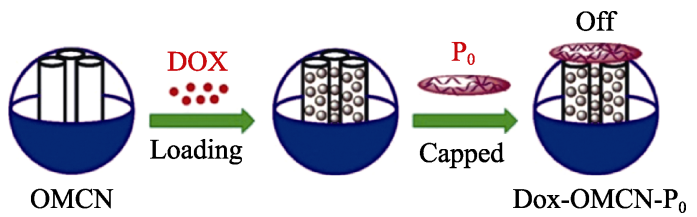

图 4 多孔碳球装载阿震素并基于 $\pi-\pi$ 作用进行通道封装 $[75]$ Fig. 4 Schematic preparation of DOX loaded on oxide mesoporous carbon nanospheres (OMCN) and its channel capped by the interaction of $\pi-\pi^{[75]}$
瘤药物载体之一 ${ }^{[45]}$ 。

\section{1 多孔碳纳米材料对抗肿瘤药物的有效 负载}

载药量是成功构建抗肿瘤药物靶向传递系统重 要的衡量指标。相对于其他的载体材料, 多孔碳纳 米材料具有孔道结构丰富、比表面积大等特点, 有 利于负载较多药物分子。

\subsection{1 提高载药量的策略}

提高载药量的关键是通过对多孔碳材料的可控 调节，增加碳质结构与药物分子之间的作用位点。 一般认为具有较大的比表面积和孔容的多孔碳纳米 材料具有更高的载药量。Kong 等 ${ }^{[78]}$ 采用简单的溶 剂热法制备了粒径为 $100 \mathrm{~nm}$, 孔径为 $2.7 \mathrm{~nm}$ 的介孔 碳纳米颗粒, 具有较大的比表面积和孔容, 以阿霉 素为模型药物，实现了 $76.1 \%$ 的高负载率。

在多孔碳纳米材料上创造空腔结构也是获得较 高载药量的有效方法。 $\mathrm{Li}$ 等 ${ }^{\left[{ }^{[9]}\right.}$ 比较了多孔碳球和中 空多孔碳球对阿霉素的载药能力, 发现具有空腔结 构的多孔碳球的载药量提升了 $10.7 \%$ 。这是由于中 空多孔结构使材料具有较大的孔容和低密度, 提供 了更多的反应位点，从而可实现更有效的药物负 载。Chen 等 ${ }^{[80]}$ 制备了红细胞形态的多孔中空碳球, 不仅阿霉素的负载量比传统的中空多孔硅纳米颗粒 提升了 $31.4 \%$, 研究还发现中空多孔碳球可以通过 沉默转移促进蛋白的表达来抑制癌细胞的转移, 具 有更好的生物相容性和传递载药性能, 因此, 中空 多孔结构是实现高载药量的重要选择。

\subsection{2 实现联合载药的策略}

为了减少给药次数, 提高对肿瘤细胞的治疗效 果，还可以通过调节多孔碳纳米材料的孔道结构实 现联合给药。

Fang 等 ${ }^{[81]}$ 以制备的双层介孔纳米碳/硅复合材 料为载体, 分别以亲水性的介孔硅层负载亲水性药 物顺铂, 疏水性的介孔碳内核负载疏水性药物紫杉 醇，实现了联合载药，不仅对人类卵巢癌细胞具有 明显的抑制作用，甚至对多药耐药细胞也具有超过 $50 \%$ 的杀灭作用(图 5(a))。抗肿瘤药物 40\%是疏水性 的， $60 \%$ 是亲水性的，传统的多孔硅纳米材料具有 亲水性，通过亲水/疏水两亲性多孔材料设计，有利 于改进抗肿瘤药物传递系统，但是其制备方法、形 貌和分级孔结构等因素对负载药物种类及抗肿瘤性 能的影响还有待研究。

$\mathrm{Du}$ 等 ${ }^{[82]}$ 以具有分级孔道结构的多孔中空碳球 为载体, 不仅有效提高了载药量, 也实现了抗癌药 物阿霉素和小干扰 RNA 的共同装载, 在减少给药 
(a) (b)

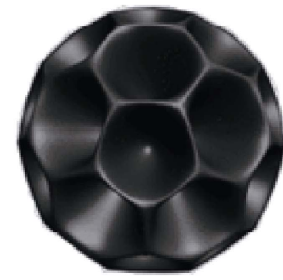

Dendrimer-like mesoporous silica nanoparticles (DMSNs)

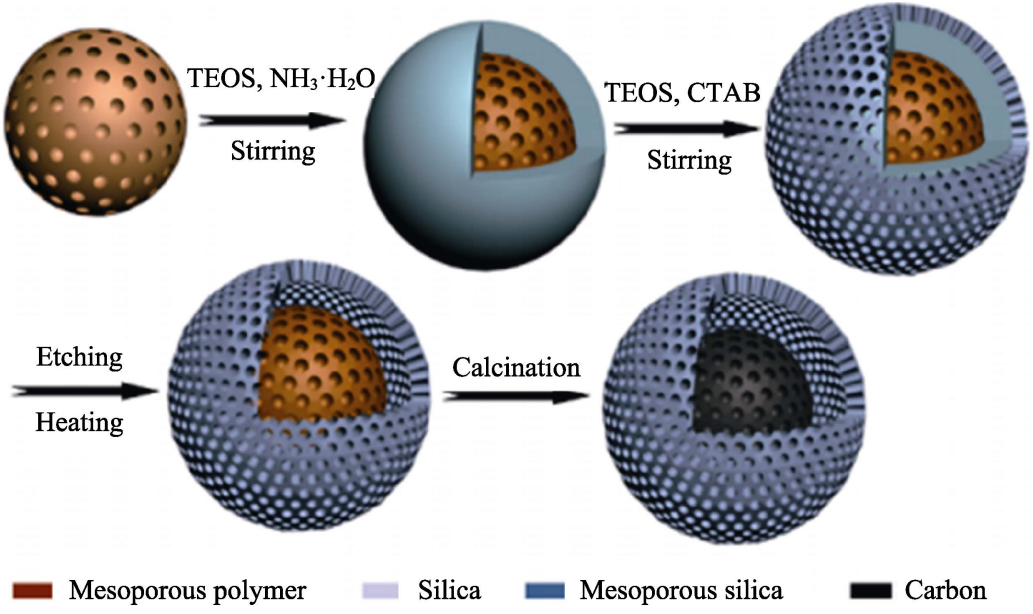

(1) Aminopropylgrafting

(2) RF coating

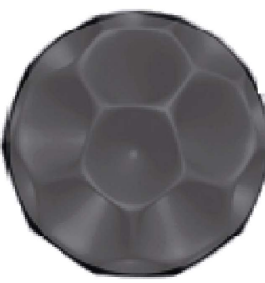

DMSNs- $\mathrm{NH}_{2} @ \mathrm{RF}$ (Tunable RF coating)
(3) Carbonization in $\mathrm{Ar}$

(4) Silica etching

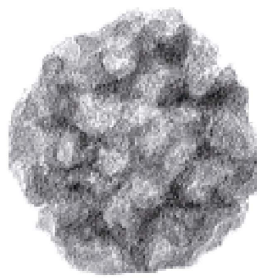

(1) $\mathrm{H}_{2} \mathrm{SO}_{4} @ \mathrm{HNO}_{3}$

(2) Short branched PEI

(3) NHIS-PEG

(TEA)

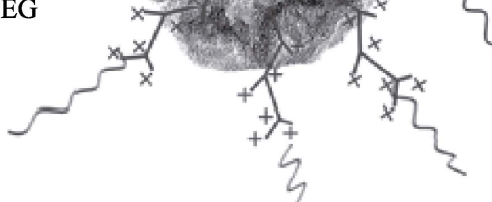

Tunable porous hollow carbon nanospheres (PHCNS) with inner surface protuberance

图 5 (a) 双孔核壳介孔碳@二氧化硅 ${ }^{[81]}$ 和(b)分级孔道多孔中空碳球装载阿霉素及小干扰 $\mathrm{RNA}^{[82]}$ 联合给药载体制备方法

Fig. 5 Schematic illustration of preparing combined administration of (a) hierarchical hybrid dual-pore core-shell mesoporous carbon@ silica $^{[81]}$ and (b) PHCNs-PEI-PEG for drug and gene co-loading ${ }^{[82]}$ DOX: doxorubicin; PEI; polyethyleneimine; PEG: poly (ethylene glycol); RF: resorcinlo-formaldehyde

次数的同时, 还提升了对肿瘤细胞的治疗效果(图 5(b)), 这是因为该结构具有独特的开放三维树状结 构, 中心具有较大尺寸的中孔, 因此, 其较高的内 比表面积为抗肿瘤药物提供了更短的扩散路径，同 时, 高度粗糙的内外表面可以大幅增加材料与药物 分子的作用位点，从而改善了装载性能。

\section{2 构建抗肿瘤药物靶向传递系统}

多孔碳纳米材料与药物的相互作用以及对肿瘤 细胞所处的微环境的敏感程度是能否实现抗肿瘤药 物靶向释放关键因素 ${ }^{[83]}$ 。将药物加载到靶向受体功 能化的多孔碳纳米材料上，利用敏感刺激构建相应 的药物传递系统, 是一种有效智能化的靶向策略。
常见的构建思路包括(表 2): (1)内源性敏感靶向，主 要基于肿瘤组织营造的独特生理环境, 如弱酸性、 氧化还原势差、酶特异性等 ${ }^{[84]}$ 。(2)外源性敏感靶向, 主要根据材料性质选择特定的外部措施, 如光热和 磁等 ${ }^{[85}$ 。(3)利用两种或多种靶向刺激要素结合, 形 成多功能增效的靶向机制。

\subsection{1 内源性敏感靶向}

(1) $\mathrm{pH}$ 敏感靶向

肿瘤细胞需要通过高速率的糖降解为其生长提 供能量, 从而产生大量乳酸堆积于肿瘤部位, 导致 肿瘤细胞周围处于弱酸环境, 其 $\mathrm{pH}$ 在 6.2 6.8, 内 涵体和溶酶体生理环境 $\mathrm{pH}$ 分别在 5.8 和 4.8 左右 ${ }^{[86]}$ 。 
表 2 多孔碳纳米材料构建抗肿瘤药物靶向传递系统

Table 2 Construction of tumor targeting drug delivery system based on porous carbon nanomaterials

\begin{tabular}{|c|c|c|c|}
\hline Structure & Response modes & Drugs & Ref. \\
\hline Porous carbon sphere & $\mathrm{pH}$ & Mitoxantrone $\mathrm{HCl}$ & {$[87]$} \\
\hline Porous carbon sphere & $\mathrm{pH}$ & Doxorubicin & {$[26]$} \\
\hline Porous carbon sphere & Specific enzyme & Doxorubicin & [91] \\
\hline Porous carbon derived from ZIF & Specific enzyme & Methylene blue & {$[35]$} \\
\hline Porous carbon sphere & Redox potential & Doxorubicin & [93] \\
\hline Hollow porous carbon sphere & Near infrared & Doxorubicin & {$[82]$} \\
\hline Porous carbon sphere & Near infrared & Doxorubicin & {$[98]$} \\
\hline Porous carbon sphere coated with $\mathrm{Fe}_{3} \mathrm{O}_{4}$ & Magnetic & Doxorubicin & [102] \\
\hline Mesoporous carbon sphere & $\mathrm{pH}-$ redox potential & Doxorubicin & $\begin{array}{l}{[104]} \\
{[105]}\end{array}$ \\
\hline Porous carbon sphere & pH-magnetic & Doxorubicin & [106] \\
\hline Ordered mesoporous carbon sphere & pH-magnetic & Doxorubicin & [107] \\
\hline Ordered mesoporous carbon spheres coated with $\mathrm{Fe}_{3} \mathrm{O}_{4}$ & Magnetic-near infrared & Doxorubicin & [108] \\
\hline Porous carbon spheres coated with $\mathrm{Au}$ and $\mathrm{Fe}_{3} \mathrm{O}_{4}$ & Magnetic-near infrared & Doxorubicin & [109] \\
\hline Hollow porous carbon sphere & pH-redox potential-near infrared & Doxorubicin & [110] \\
\hline
\end{tabular}

因此，利用肿瘤细胞和正常组织细胞的微环境 $\mathrm{pH}$ 差异来设计制备 $\mathrm{pH}$ 依赖型药物载体, 在肿瘤部位 弱酸环境中实现药物释放, 是常见的多孔碳纳米材 料装载抗肿瘤药物实现靶向释放的重要途径之一。 如图 6 所示, Huang 等 ${ }^{[87]}$ 以多孔碳球为载体, 负载了 盐酸米托葱醌, 使用 $N$-(3-三甲氧基甲硅烷基丙基) 乙二胺三乙酸酯官能化的 $\mathrm{ZnO}$ 量子点, 通过双酰胺 键与修饰过的介孔碳球以共价作用连接封装, 构建 了 $\mathrm{pH}$ 敏感刺激响应药物传递系统, 成功实现了药

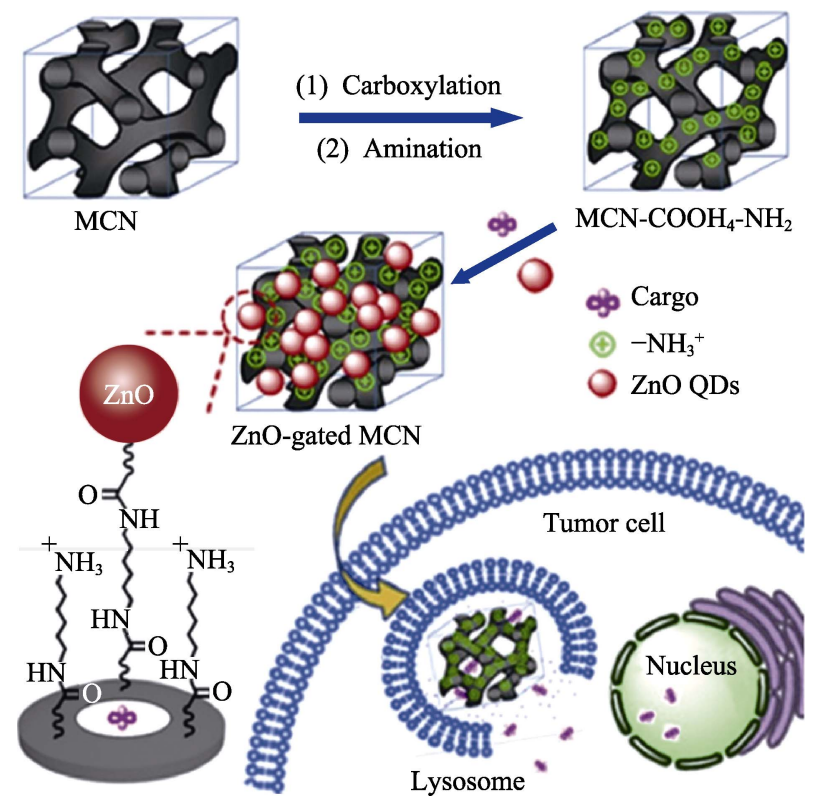

图 $6 \mathrm{ZnO}$ 门控多孔碳球的 $\mathrm{pH}$ 响应性控制释放示意图 ${ }^{[87]}$

Fig. 6 Schematic illustration of pH-responsive controlled release of $\mathrm{ZnO}$-gated $\mathrm{MCNs}^{[87]}$

MCN: mesoporous carbon nanoparticles
物在酸性介质中的快速释放。Zhu 等 ${ }^{[26]}$ 制备了粒径 为 $90 \mathrm{~nm}$ 的多孔碳球, 通过装载酸敏感性药物阿霉 素, 考察了不同 $\mathrm{pH}$ 环境下的负载和释放行为, 发现 合适粒径的多孔碳球更易于携带阿霉素内化到宫颈 癌细胞中, 并在酸性条件下发挥靶向治疗作用, 体 现了良好的抗肿瘤特性。

由文献 ${ }^{[26]}$ 可知, 直径小于 $100 \mathrm{~nm}$ 的多孔碳球 具备发展为抗肿瘤药物跨膜载体的潜力, 但需经过 表面亲水性修饰，最大限度地提高循环次数。同时， 由于肿瘤细胞中内涵体和溶酶体生理环境的酸性更 加明显, 对于碱性修饰过的多孔碳药物传递系统可 能具有促进释放的作用, 从而提高靶向性能, 因此, 通过合理设计，制备尺寸合适的多孔碳纳米材料， 有望实现抗肿瘤药物传递系统的 $\mathrm{pH}$ 敏感靶向释放。

\section{(2)酶感靶向}

许多肿瘤组织会过度分泌某些特定的酶 ${ }^{[88]}$, 这 为构建酶特异性敏感的靶向药物传递系统提供了思 路。核酸适配体是一小段经体外篎选得到的寡核苷 酸序列或者短多肽, 采用核酸适配体对纳米颗粒进 行表面修饰可与特定的酶或 DNA 序列形成高亲和 力和强特异性的结合, 从而构建高敏感的靶向特异 性识别系统 ${ }^{[89]}$ 。细胞表面粘蛋白 MUC1 是一种 I 型 跨膜蛋白, 在多种肿瘤细胞中表达异常, 可达正常 时的 100 倍以上, 是一种重要的肿瘤生物学靶标 ${ }^{[00]}$,

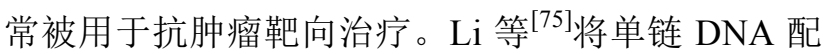
对链涂覆在多孔碳球表面, 以阿霉素为模型药物, 利用 MUC1 粘蛋白标志物与单链 DNA 配对链特异 性结合，通过 $\pi-\pi$ 作用封装多孔碳球的孔道，实现 
了阿霉素的靶向传递。溶菌酶有一定的抗癌能力, 在生物医学领域有着很大的应用潜力 ${ }^{[91]}$ 。Cao 等 ${ }^{[35]}$ 以 ZIF-8 衍生的多孔碳纳米材料为载体, 经羒化后, 进一步与胺修饰的单链 DNA 偶联, 通过溶菌酶核 酸配体组成的 DNA 双链在载体表面上进行封装, 实 现了对亚甲基蓝的负载, 通过对溶菌酶的响应, 实 现了 DNA 双链解离, 靶向性地释放了亚甲基蓝, 其 合成及释放过程见图 7。使用特异性蛋白结合多孔碳 纳米材料, 相当于在材料的通道入口安装了稳健的 生物传感器“开关”, 以激活药物传递系统, 更加精准 地实现靶向给药, 具有毒性小、治疗指数高等优点。

(3)氧化还原反应敏感靶向

肿瘤细胞内谷胱甘肽的浓度比正常细胞高出数

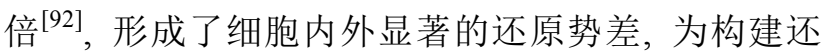
原敏感的靶向传递系统提供了条件。Zhou 等 ${ }^{[93]}$ 通过 二硫键在多孔碳球表面修饰透明质酸, 并负载阿霉 素, 构建了载药系统, 该载药系统可同时对细胞内 的谷胱甘肽和透明质酸酶进行响应, 从而实现了阿 霉素按需可控释放。由于代谢异常, 肿瘤细胞内还 含有大量的活性氧，从而使肿瘤细胞内具有显著的 氧化能力 ${ }^{[94-95]}$ 。利用对活性氧敏感的化学键构建氧 化敏感抗肿瘤药物靶向传递系统也是一种可行的方 式。王琳召等 ${ }^{[96]}$ 分别用聚乙烯吡咯烷酮和培化磷脂 酰乙醇胺对多孔碳球表面进行修饰，考察了其对宫 颈癌细胞氧化应激状态下细胞活力的影响, 发现经 过聚乙烯吡咯烷酮修饰后的多孔碳球能明显减少活 性氧的产生, 为构建氧化刺激响应的多孔碳纳米材 料载药系统提供了重要依据。

\subsection{2 外源性敏感靶向}

(1)光敏感靶向

由于肿瘤细胞的异常生理, 导致其对热的敏感 性更强。多孔碳纳米材料可以吸收近红外区域(NIR I : 700 1100 nm, NIR II : 1 1.4 $\mu \mathrm{m})$ 中的光能, 并

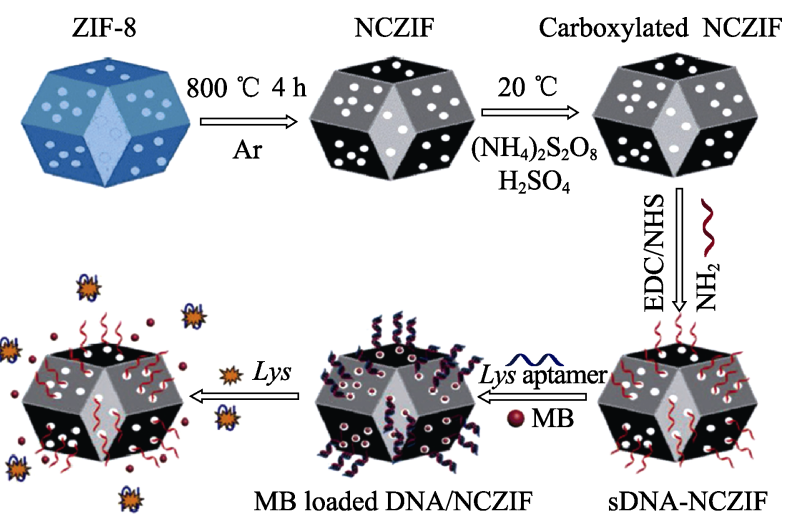

图 7 ZIF 热解获得的多孔碳球酶敏感响应示意图 ${ }^{[35]}$

Fig. 7 Schematic illustration of enzyme-responsive of porous carbon obtained from ZIF pyrolysis ${ }^{[35]}$
以热能的形式散发，在短时间内局部温度升至 $40 \sim 45{ }^{\circ} \mathrm{C}$, 高于生理温度 $37{ }^{\circ} \mathrm{C}$, 从而诱导对癌细 胞的热破坏 ${ }^{[97]}$ 。 $\mathrm{Du}$ 等 ${ }^{[82]}$ 采用带正电荷的聚乙烯亚 胺修饰多孔中空碳球表面, 构建了大尺寸基因分子 与阿霉素同时负载的药物传递系统，结果表明，该 系统可以有效地将近红外光转化为热能, 在基因治 疗的协同作用下，几乎杀死了所有癌细胞。 $\mathrm{Xu}$ 等 ${ }^{[98]}$ 采用聚乙烯亚胺和叶酸对多孔碳纳米材料进行修饰, 构建了化学光热靶向的药物传递载体, 发现将化学 疗法与光热疗法相结合, 可以发挥更好的治疗功效 (图 8)。因此, 光敏感是构建抗肿瘤药物传递系统常 用的体外敏感刺激方式。

(2)磁敏感靶向

在外部交变磁场中, 磁性纳米粒子可以通过 Néel 弛豫损耗产生热量 ${ }^{[99]}$, 将磁能转化为热能, 从 而引起局部温度升至有效治疗温度, 使用磁靶向药 物载体时, 将磁场置于目标位置能显著提高药物在 病灶的积累 ${ }^{[100-101]}$ 。 $\mathrm{Wu}$ 等 ${ }^{[102]}$ 利用 $\mathrm{Fe}_{3} \mathrm{O}_{4}$ 为造影剂 和磁性靶向剂, 制备了多孔碳包覆 $\mathrm{Fe}_{3} \mathrm{O}_{4}$ 纳米粒子, 依次通过乙二胺和透明质酸修饰, 以阿霉素药物模 型, 构建了靶向药物传递系统, 研究表明该系统具 有良好的生物相容性和光热转化能力, 对宫颈癌细 胞具有良好的杀伤效果(图 9)。

\subsection{3 多功能协同靶向}

将两种或多种敏感靶向方法相结合，可以产生 协同诱导作用，有利于提高多孔碳纳米材料药物传 递系统载药能力、增强靶向释放性能、改良药物传 递性能，同时也可降低细胞毒性、减少药物的使用 剂量并降低副作用 ${ }^{[103]}$ 。因此，构建双敏感刺激或多 刺激响应的药物传递载体，利用其多重控释和协同 抗癌功能, 可以有效解决单敏感药物释放刺激不足, 实现更有效、更完全的药物释放, 在诊断和高效治 疗肿瘤方面具有重要意义。

(1) $\mathrm{pH}$ 和谷胱甘肽双敏感靶向

Zhang 等 ${ }^{[104]}$ 采用聚丙烯酸对介孔碳球孔道进 行封装，制备了对 $\mathrm{pH}$ 和谷胱甘肽双敏感响应的药 物载体, 一方面, 在细胞内酸性环境诱导下, 聚丙 烯酸(PAA)门控部分释放; 另一方面, 通过还原型 谷胱甘肽破坏药物载体的完整性, 实现了药物的可 控释放。在后续的研究中 ${ }^{[105]}$, 通过将粘蛋白配体 MUC1 针定在多孔碳球表面上, 提供特异性识别癌 细胞的能力, 可实现阿霉素的靶向释放, 对人肺腺 癌细胞和乳腺癌细胞可进行靶向识别和治疗(图 10)。

(2) $\mathrm{pH}$ 和磁双敏感靶向

Yang 等 ${ }^{[106]}$ 采用 $\mathrm{pH}$ 敏感的 $\mathrm{ZnO}$ 量子点对多孔 碳球进行封装, 利用 $\mathrm{Fe}_{3} \mathrm{O}_{4}$ 为磁性诱发剂, 构建了 


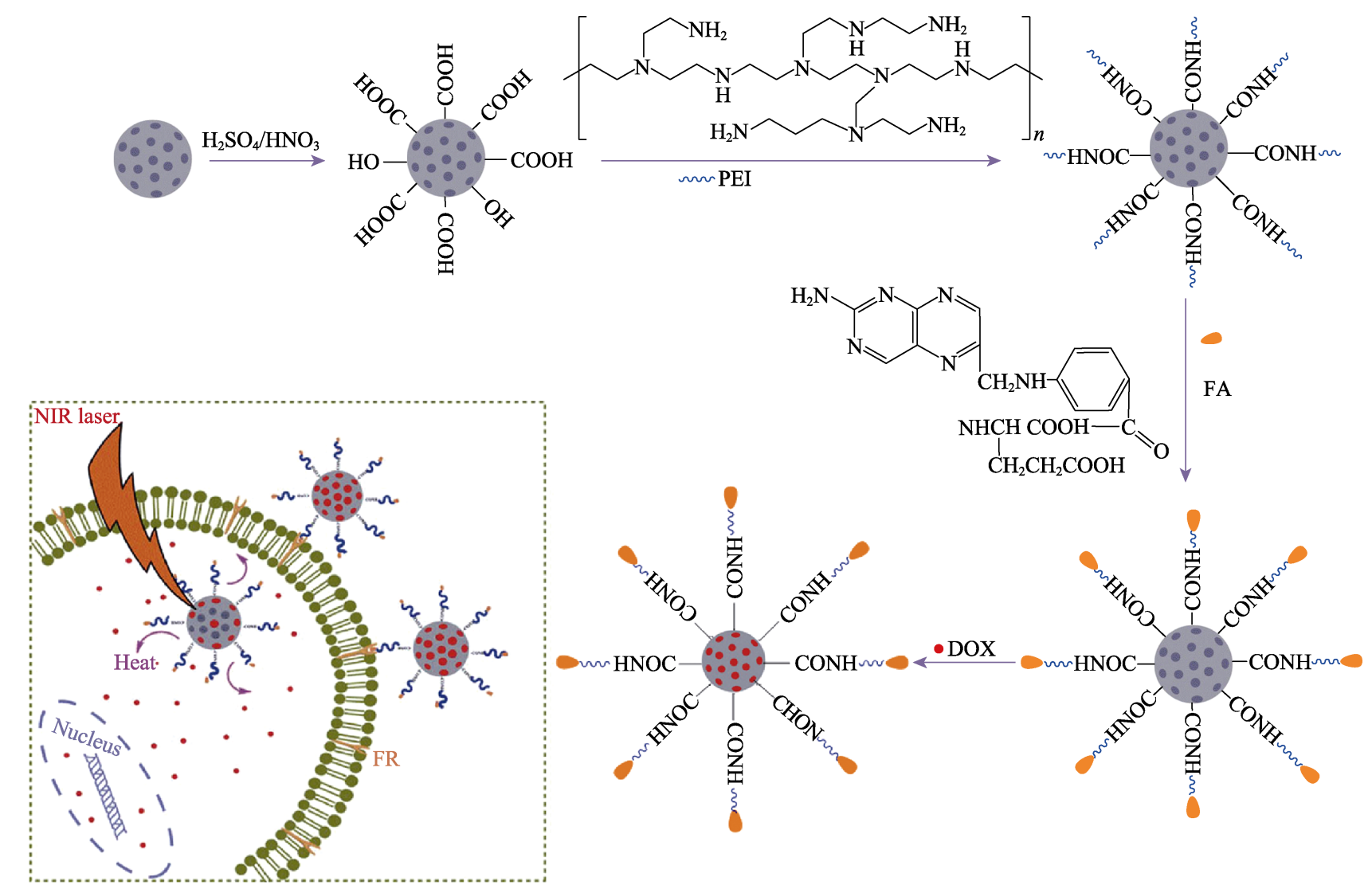

图 8 多孔中空碳球的修饰及光热响应示意图 ${ }^{[98]}$

Fig. 8 Schematic illustration of modified porous hollow carbon spheres and the photothermal therapy ${ }^{[98]}$

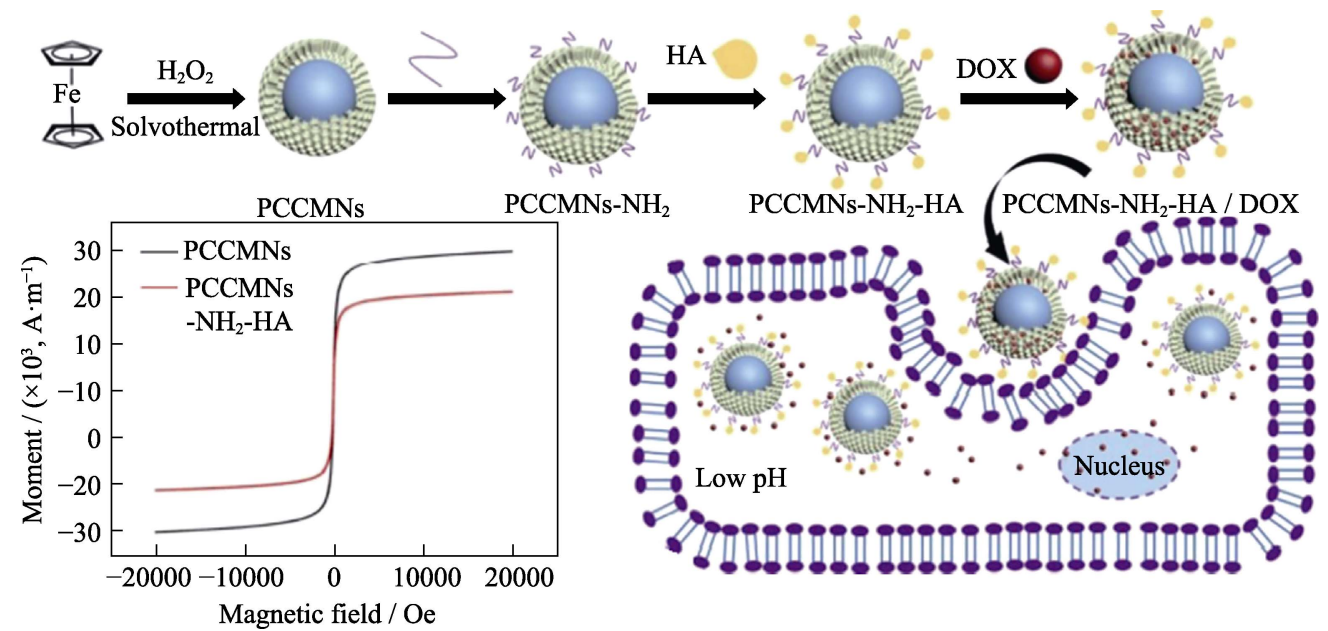

图 9 多孔碳包覆 $\mathrm{Fe}_{3} \mathrm{O}_{4}$ 纳米粒子并负载阿霉素的制备 ${ }^{[102]}$

Fig. 9 Schematic illustration of $\mathrm{MCNs}$ coated $\mathrm{Fe}_{3} \mathrm{O}_{4}$ nanoparticles and DOX loaded ${ }^{[102]}$ PCCMNs: porous carbon coated magnetic nanoparticles; DOX: doxorubicin; $1 \mathrm{Oe} \approx 79.62 \mathrm{~A} / \mathrm{m}$

$\mathrm{pH}$ 和磁性敏感双触发药物传递系统，不仅实现了 较高的药物负载率, 还实现了 $\mathrm{pH}$ 和磁性双敏感靶 向释放(图 11)。Chen 等 ${ }^{[107]}$ 以叶酸偶联磁性有序多 孔碳球为载体, 阿霉素为模型药物, 构建了 $\mathrm{pH}$ 和磁 性双敏感药物传递系统。在有效的靶向作用下, 药 物可以很容易地被内化到癌细胞中, 提高了治疗作 用，同时载体的保护作用使阿霉素在体内循环过程
中对正常组织细胞的毒性作用大幅减小。

(3)磁和光热双敏感靶向

Chen 等 ${ }^{[108]}$ 制备了具有热敏性和磁性双功能的 有序介孔碳球, 以阿霉素为模型药物, 实现了阿霉 素可控释放, 为构建双敏感抗肿瘤药物传递系统提 供了新思路(图 12)。Wang 等 ${ }^{[109]}$ 制备了纳米金和 $\mathrm{Fe}_{3} \mathrm{O}_{4}$ 共同修饰的多孔碳材料, 构建了磁性一近红外 


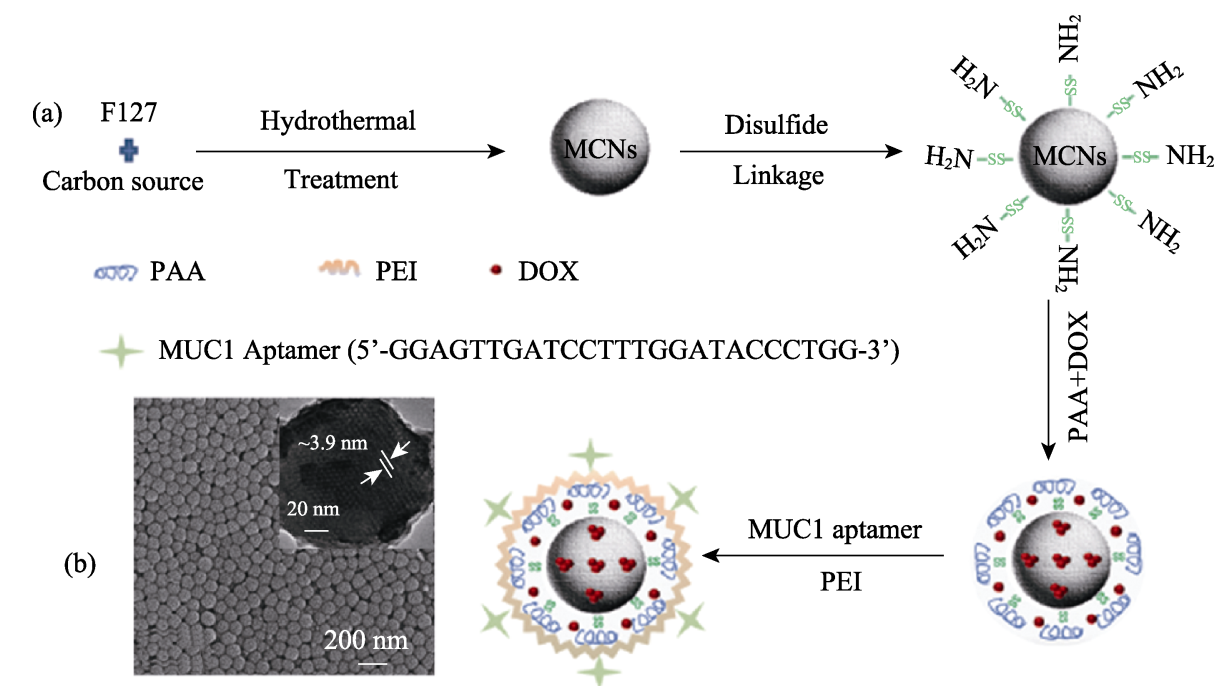

图 10 制备 $\mathrm{pH}$ 和谷胱甘肽双敏感的多孔碳球示意图 ${ }^{[105]}$

Fig. 10 Schematic preparation of MCN responsive controlled release by $\mathrm{pH}$ and glutathione $\mathrm{e}^{[105]}$ PAA: polyacrylic acid; PEI: polyc (ethyllene glycol); DOX: doxorubicin

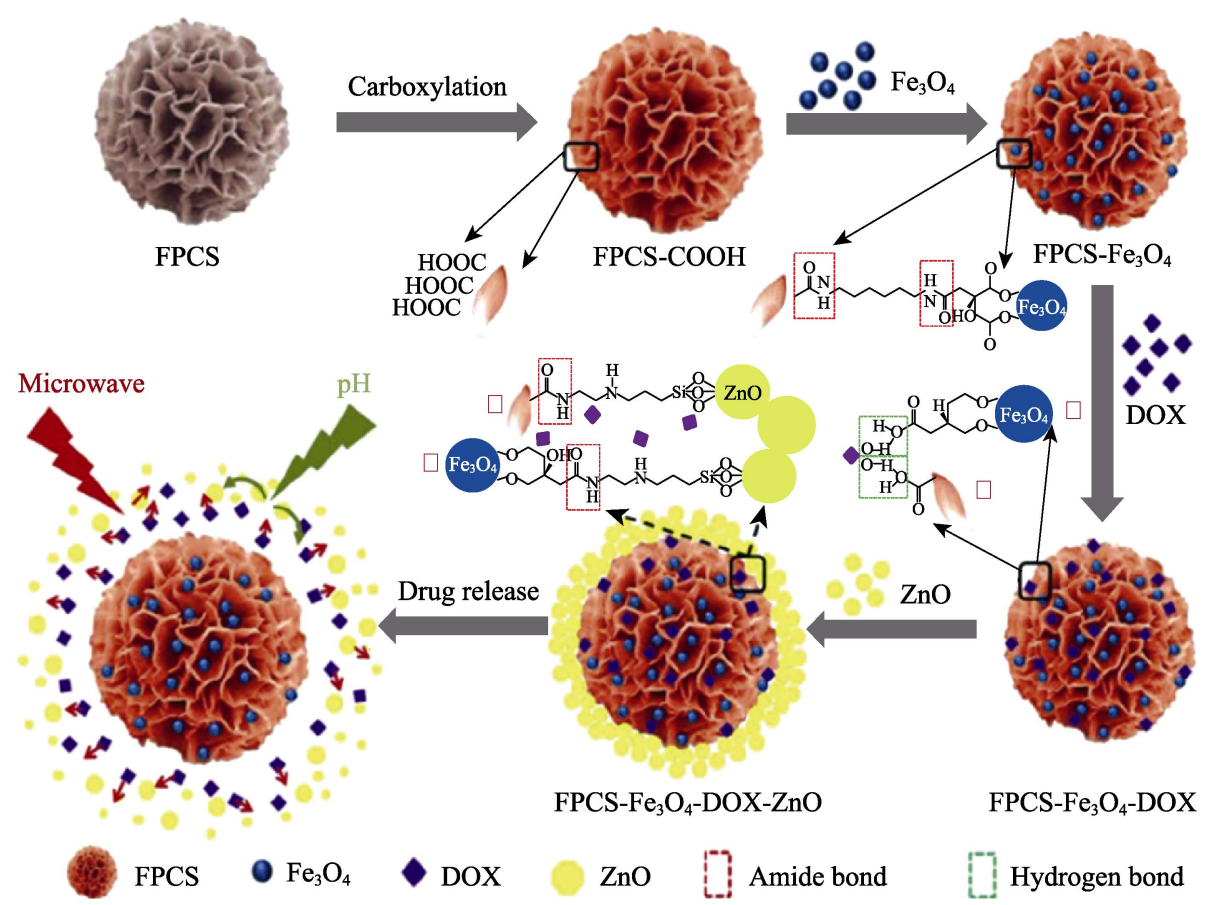

图 11 利用花状多孔碳球构建 $\mathrm{pH}$ 和磁复合敏感材料 ${ }^{[106]}$

Fig. 11 Schematic illustration of construction of $\mathrm{pH}$ and magnetic composite sensitive materials by flower-like porous carbon composite $(\mathrm{FPCS})^{[106]}$

DOX: doxorubicin

双功能敏感药物传递系统, 该系统可在交变磁场中 产生局部化热，从而引发阿霉素释放，近红外光热 效应在调节药物释放速率的同时，还可以有效地杀 伤肿瘤细胞, 发挥了磁热与光热的协同作用的效 果。与单一的敏感刺激相比, 双敏感刺激可以更好 地发挥协同效应，对肿瘤细胞更具有杀伤力。

(4) $\mathrm{pH}$ 、谷胱甘肽和光热多敏感靶向 $\mathrm{Wu}$ 等 ${ }^{[110]}$ 以磁性空心多孔碳球为载体, 以阿霉
素为模型药物, 采用聚 $\gamma$-谷氨酸作为通道封装剂, 构建了具有 $\mathrm{pH}$ 、谷胱甘肽和红外光三重响应特征的 靶向药物传递系统，对肿瘤细胞微环境具有多重敏 感协同治疗效果，不仅实现了优异的抗肿瘤靶向治 疗能力, 还有效地阻止了药物在到达靶位点之前释 放, 解决了对正常细胞的不良影响(图 13)。与单敏 感和双敏感刺激的药物传递系统相比, 三敏感刺激 可以实现更有效和更完全的药物释放。 


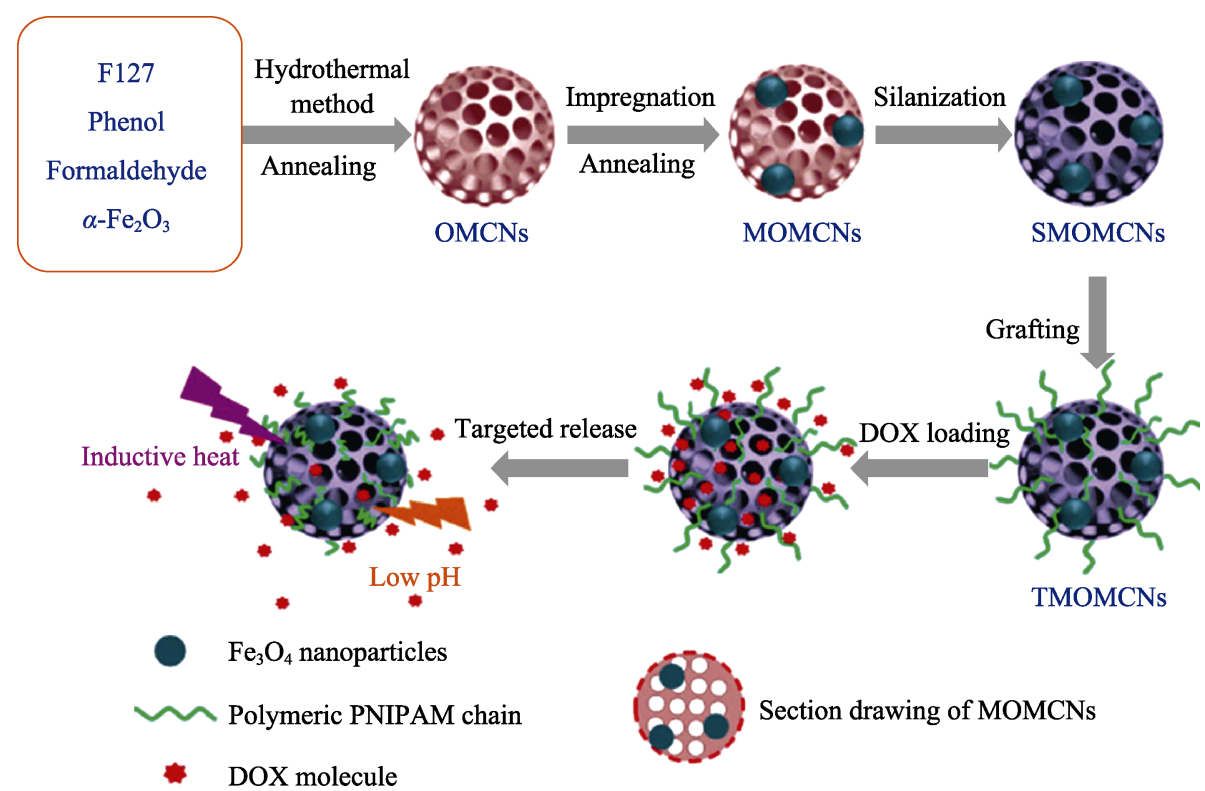

图 12 磁热、光热能双敏感释放药物传递载体构建示意图 ${ }^{[108]}$

Fig. 12 Schematic illustration of construction drug delivery by $\mathrm{pH}$ and magnetic composite sensitive ${ }^{[108]}$ OMCNs: ordered mesoporous carbon nanospheres; MOMCNs: magnetically OMCNs;

TMOMCNs: thermo-sensitiuely MOMCNs; SMOMCNs: silane modified MOMCNs; DOX: doxorubicin

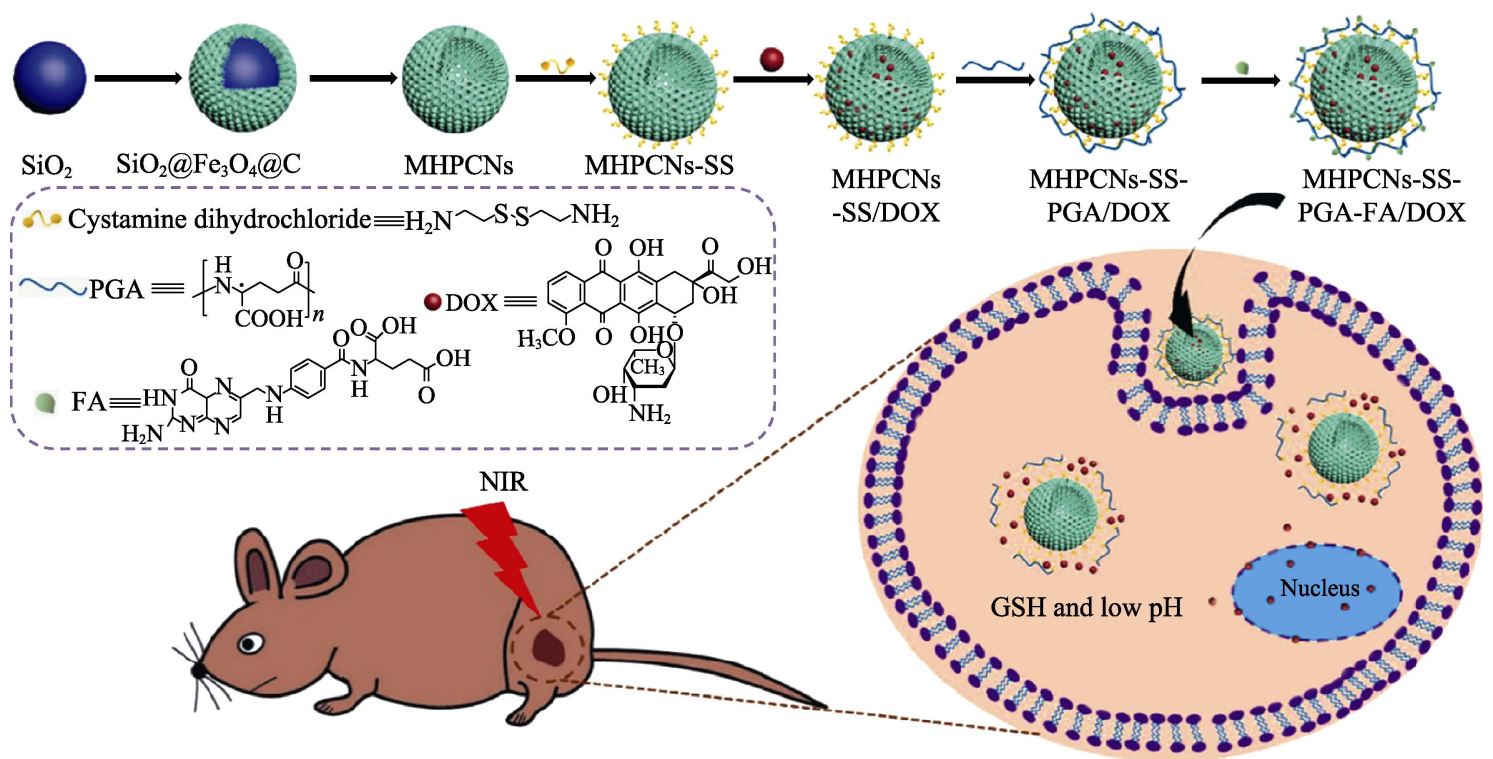

图 13 肿瘤化疗 $\mathrm{pH}$ 、谷胱甘肽和光热化疗协同刺激反应药物传递系统的合成示意图 ${ }^{[110]}$

Fig. 13 Schematic preparation of stimuli-responsive MHPCNs based drug delivery system for synergistic $\mathrm{pH}$, glutathione and photothermal of tumor chemotherapy ${ }^{[110]}$

MHPCNs: magnetic hollow porous carbon nanoparticles

\section{3 多孔碳纳米材料的安全性和降解性}

\section{1 多孔碳纳米材料的生物安全性}

良好的生物安全性是多孔碳纳米材料应用于生 物医学领域的基础，是其在体内使用的先决条件。

目前, 关于多孔碳纳米材料的生物相容性研究 大多集中于体外细胞毒性方面。研究表明, 当多孔
碳纳米材料的浓度约 $200 \mu \mathrm{g} \cdot \mathrm{mL}^{-1}$ 时, 对多种细胞 均具有可忽略的细胞毒性, 该浓度已远大于最大的 临床使用浓度 $\left(50 \mu \mathrm{g} \cdot \mathrm{mL}^{-1}\right)^{[72,74,106]}$ 。多孔碳纳米材料 的表面化学特性是影响其细胞毒性的重要因素, 其 表面的高活性化学基团(如不饱和键、羰基、羧基、 羟基等)易反应生成氧自由基，从而损伤细胞，产生 毒性, 因此, 高活性化学基团的增多可一定程度上 增强碳纳米材料的细胞毒性 ${ }^{[71]}$ 。 $\mathrm{Li}$ 等 ${ }^{[74]}$ 以蔗糖为碳 
源, 以十六烷基三甲基溴化铵为表面活性剂获得的 多孔碳纳米球，与不添加表面活性剂相比, 由于具 有较为丰富的表面活性基团, 易于形成活性氧自由 基，从而对细胞表现出了一定的毒性，不过，增强 幅度有限。同时，对多孔碳纳米材料进行表面修饰 可以防止药物在传递过程中的非特异性释放，从而 可降低载药系统的细胞毒性, 提高系统的生物相容 性。 $\mathrm{Xu}$ 等 ${ }^{[98]}$ 通过测定细胞计数和乳酸脱氢酶活性, 证实了经聚乙烯亚胺和叶酸共同修饰的多孔碳纳米 材料对 HeLa 细胞没有明显的细胞毒性, 生物相容 性良好。 $\mathrm{Li}$ 等 ${ }^{[79]}$ 通过流式细胞仪分析经羧基修饰的 中空多孔碳球的细胞毒性, 结果表明细胞存活率保 持在 $80 \%$ 以上。由此可知，在体外细胞毒性方面，以 多孔碳纳米材料构建药物传递系统具有良好的生物 相容性。

体内生物安全是多孔碳纳米材料在生物医学领 域应用发展的重要问题。Wu 等 ${ }^{[110]}$ 制备了磁性中空 多孔碳球作为抗肿瘤药物阿霉素的载体, 并将阿霉 素药物本身作为对照组, 考察对小鼠机体的生物毒 性, 结果表明, 由于阿霉素的毒性和副作用, 药物 组小鼠的重量明显下降, 而药物载体系统组的体重 没有明显减少, 主要脏器(心、肝、脾、肺、肾)的组 织学分析结果显示无明显脏器损害或脏器改变, 进 一步确证了多孔碳纳米材料对机体的生物安全性, 因此, 多孔碳纳米材料有望成为高效抗肿瘤治疗的 纳米平台。

\section{2 多孔碳纳米材料的生物降解性}

多功能修饰的多孔碳纳米材料由于具有低细胞 毒性和高效抗肿瘤特性，从而具有广阔的抗肿瘤前 景, 但由于其碳骨架结构的稳固性, 导致生物降解 性能较差, 并且在体内积聚过多可能会产生长期的 生物毒性，这极大地阻碍了其进一步的临床应用， 因此, 开发可降解或可清除的多孔碳纳米材料具有 重要意义。

多孔硅纳米材料具有良好的生物降解性 ${ }^{[111]}$ 。通 过将其与具有良好生物相容性和结构稳定性的多孔 碳纳米材料相结合可制备生物降解性能良好的复合 型纳米材料。Zhang 等 ${ }^{[12]}$ 制备了包覆碳壳的中空多 孔硅纳米球, 通过酸处理将羧基和羟基附着在碳壳 上, 提高了材料的亲水性, 经阿霉素加载和聚乙二 醇修饰后, 设计了兼具高载药量、 $\mathrm{pH}$ 和光热双敏感 特性的药物载体, 将该纳米材料在模拟生理环境的 缓冲溶液中震荡 $30 \mathrm{~d}$, 通过 SEM 和 TEM 观察震荡 前后的形貌，可以清楚地观察到震荡后碳材料的坍 塌、断裂等形态变化，同时，震荡后的缓冲溶液中硅
的质量浓度从 $0.35 \%$ 上升到了 $8.4 \%$ ，证实了包覆碳 壳的中空多孔硅纳米球的降解。复合材料可降解性 增加的原因可能在于复合元素的掺入, 这些元素与 碳元素之间形成的结合键容易打开，降低了碳骨架 的坚固性。

另外, 大多数纳米粒子在组织器官中的可清除 性可能受其粒径大小和组成的影响 ${ }^{[113]}$, 机体对于 不规则形状或粒径较大的碳纳米粒清除较困难 ${ }^{[72]}$, 因此，通过制备不同元素复合，或控制多孔碳纳米 材料的形状和尺寸, 可能实现其生物降解性或可清 除性能的提高。

\section{4 结语与展望}

近年来，癌症作为严重威胁我国居民健康的重 大疾病，对国家经济和社会的可持续发展造成了极 大的负担。由于多孔碳纳米材料具有独特的物理特 性、化学多功能性和出色的药物负载能力, 使其具 备了作为有效的癌症治疗剂的先决条件 ${ }^{[65]}$ 。采用多 孔碳纳米材料为载体, 融合物理、化学作用协同增 效, 构建兼具高负载能力和靶向识别肿瘤功能的抗 肿瘤药物传递系统, 为肿瘤的诊治提供了重要方向。

目前，采用多孔碳纳米材料构建靶向传递系统 在基础研究方面取得了很多进展，但仍然存在一些 问题尚待解决，比如，现有方法合成大量的具有分 散性良好、尺寸均一、高比表面积等适宜载药需求 的多孔碳材料仍然面临挑战，同时，多孔碳纳米材 料的结构特征和修饰与体内外生物相容性、生物降 解性的关系尚不够明确。更重要的是，多孔碳纳米 材料与其生物降解性的相关研究较少, 不能为开展 临床研究提供足够的数据支撑。

因此, 要实现多孔碳材料在生物医药领域有效 临床转化, 还有很多问题需要继续探索: (1)设计结构 更加可控的多孔碳纳米材料及其绿色制备方法, 实 现载体对药物分子的高效负载。(2)探索更丰富的表 面修饰方法，实现多孔碳纳米材料在体内循环代谢 过程中生物相容性良好。(3)考察多孔碳纳米材料结 构特征对生物毒性和在不同组织器官中保留时间的 影响因素, 形成不同结构形貌和器官降解清除的规 律性认识。(4)深入研究肿瘤微环境敏感机制, 有针对 性地设计载药多孔碳纳米材料更加有效的靶向策 略。(5)建立规范化的适用于临床应用的检测标准，保 证临床转化成果可持续推广应用。我们相信, 随着科 研工作的不断深入，将会有越来越多基于多孔碳纳 米材料的靶向抗肿瘤药物传递系统应用于临床治疗。 


\section{参考文献:}

[1] BRAY F, FERLAY J, SOERJOMATARAM I, et al. Global cancer statistics 2018: GLOBOCAN estimates of incidence and mortality worldwide for 36 cancers in 185 countries. CA: A Cancer Journal for Clinicians, 2018, 68(6): 394-424.

[2] CHEN J G, CHEN H Z, ZHU J, et al. Cancer survival in patients from a hospital-based cancer registry, China. Journal of Cancer, 2018, 9(5): 851-860.

[3] FAN W, LU N, HUANG P, et al. Glucose-responsive sequential generation of hydrogenperoxide and nitric oxide for synergistic cancer starving-like/gas therapy. Angewandte Chemie, International Edition in English, 2017, 56(5): 1229-1233.

[4] LINDNER O C, PHILLIPS B, MCCABE M G, et al. A meta-analysis of cognitive impairment following adult cancer chemotherapy. Neuropsychology, 2014, 28(5): 726-740.

[5] MILLER K D, NOGUEIRA L, MARIOTTO A B, et al. Cancer treatment and survivorship statistics, 2019. CA: A Cancer Journal for Clinicians, 2019, 69(5): 363-385.

[6] ZHAO X, TIAN K, ZHOU T, et al. PEGylated multi-walled carbon nanotubes as versatile vector for tumor-specific intracellular triggered release with enhanced anti-cancer efficiency: Optimization of length and PEGylation degree. Colloids and Surfaces B: Biointerfaces, 2018, 168(1): 43-49.

[7] ZHOU S, SHA H, LIU B, et al. Integration of simultaneous and cascade release of two drugs into smart single nanovehicles based on DNA-gated mesoporous silica nanoparticles. Chemical Science (Royal Society of Chemistry: 2010), 2014, 5(11): 4424-4433.

[8] GUO T, ZHU J, YANG Y, et al. Progress in the construction and application of nano drug delivery systems based on Bletilla striata polysaccharides. Chinese Journal of Pharmaceuticals, 2019, 50(9): 958-967.

[9] SHI J, WANG B, WANG L, et al. Fullerene (C60)-based tumor-targeting nanoparticles with "off-on" state for enhanced treatment of cancer. Journal of Controlled Release, 2016, 235(10): 245-258.

[10] MEHER J G, KESHARWANI P, CHAURASIA M, et al. Carbon nanotubes (CNTs): A novel drug delivery tool in brain tumor treatment. London: Academic Press, 2018: 375-396.

[11] XIANWU HUA, YAN-WEN BAO, WU F-G. Fluorescent carbon quantum dots with intrinsic nucleolus-targeting capability for nucleolus ilmaging and enhanced cytosolic and nuclear drug delivery. ACS Appl. Mater. Interfaces, 2018, 10(13): 10664-10677.

[12] CHEN Y, TAN C, ZHANG H, et al. Two-dimensional graphene analogues for biomedical applications. Chemical Society Reviews, 2015, 44(9): 2681-2701.

[13] WEI Y, ZHOU F, ZHANG D, et al. A graphene oxide based smart drug delivery system for tumor mitochondria-targeting photodynamic therapy. Nanoscale, 2016, 8(6): 3530-3538.

[14] HE B, SHI Y, LIANG Y, et al. Single-walled carbon-nanohorns improve biocompatibility over nanotubes by triggering less protein-initiated pyroptosis and apoptosis in macrophages. Nature Communications, 2018, 9(1): 2393-2399.

[15] SAHA D, HELDT C L, GENCOGLU M F, et al. A study on the cytotoxicity of carbon-based materials. Materials Science \& Engineering. C: Materials for Biological Applications, 2016, 68(1): 101-108.

[16] SONG M, YUAN S, YIN J, et al. Size-dependent toxicity of nano-C60 aggregates: more sensitive indication by apoptosis-related Bax translocation in cultured human cells. Environmental Science \& Technology, 2012, 46(6): 3457-3464.

[17] ALlEGRI M, PERIVOLIOTIS D K, BIANCHI M G, et al. Toxicity determinants of multi-walled carbon nanotubes: The relationship between functionalization and agglomeration. Toxicology Reports, 2016, 3: 230-243.

[18] KIM T W, CHUNG P W, SLOWING, II, et al. Structurally ordered mesoporous carbon nanoparticles as transmembrane delivery vehicle in human cancer cells. Nano Letters, 2008, 8(11): 3724-3727.

[19] GOBBO O L, SJAASTAD K, RADOMSKI M W, et al. Magnetic nanoparticles in cancer theranostics. Theranostics, 2015, 5(11): $1249-1263$.

[20] ZHAO Q, LIN Y, HAN N, et al. Mesoporous carbon nanomaterials in drug delivery and biomedical application. Drug Delivery, 2017, 24(2): 94-107.

[21] SHRESTHA $\mathrm{R}$ G, MAJI S, SHRESTHA L $\mathrm{K}$, et al. Nanoarchitectonics of nanoporous carbon materials in supercapacitors applications. Nanomaterials, 2020, 10(4): 639-1-27.

[22] CHENG Y J, LUO G F, ZHU J Y, et al. Enzyme-induced and tumor-targeted drug delivery system based on multifunctional mesoporous silica nanoparticles. ACS Applied Materials \& Interfaces, 2015, 7(17): 9078-9087.

[23] CHEN Y, SHI J. Mesoporous carbon biomaterials. Science China Materials, 2015, 58(3): 241-257.

[24] MENG Y, WANG S, LI C, et al. Photothermal combined gene therapy achieved by polyethyleneimine-grafted oxidized mesoporous carbon nanospheres. Biomaterials, 2016, 100: 34-142.

[25] PEI F, AN T, ZANG J, et al. From hollow carbon spheres to $\mathrm{N}$-doped hollow porous carbon bowls: rational design of hollow carbon host for Li-S batteries. Advanced Energy Materials, 2016, 6(8): 1502539

[26] ZHU J, LIAO L, BIAN X, et al. pH-controlled delivery of doxorubicin to cancer cells, based on small mesoporous carbon nanospheres. Small, 2012, 8(17): 2715-2720.

[27] WU F, LIU Y, LU X, et al. Controllable preparation of polydopamine modified gold nanoflowers and its application in photothermal therapy. Chemical Journal of Chinese Universities, 2020, 41(3): 465-472.

[28] TIAN W, ZHANG H, DUAN X, et al. Porous carbons: structure-criented design and versatile applications. Advanced Functional Materials, 2020, 30: 1909265.

[29] LI S, CHENG C, ZHAO X, et al. Active salt/silica-templated 2D mesoporous $\mathrm{FeCo}-\mathrm{NX}$-carbon as bifunctional oxygen electrodes for zinc-air batteries. Angewandte Chemie, International Edition in English, 2018, 57(7): 1856-1862.

[30] BENZIGAR M R, JOSEPH S, ILBEYGI $\mathrm{H}$, et al. Highly crystalline mesoporous $\mathrm{C} 60$ with ordered pores: a class of nanomaterials for energy applications. Angewandte Chemie, International Edition in English, 2018, 57(2): 569-573.

[31] ZHANG P, WANG L, YANG S, et al. Solid-state synthesis of ordered mesoporous carbon catalysts via a mechanochemical assembly through coordination cross-linking. Nature Communications, 2017, 8: 15020.

[32] ZHANG Z, JIA B, LIU L, et al. Hollow multihole carbon bowls: a stress-release structure design for high-stability and high-volumetric-capacity potassium-ion batteries. ACS Nano, 2019, 13(10): 11363-11371.

[33] PENG L, HUNG C T, WANG S, et al. Versatile nanoemulsion assembly approach to synthesize functional mesoporous carbon nanospheres with tunable pore sizes and architectures. Journal of the American Chemical Society, 2019, 141(17): 7073-7080.

[34] LI Q, GUO J, ZHU H, et al. Space-confined synthesis of ZIF-67 nanoparticles in hollow carbon nanospheres for $\mathrm{CO}_{2}$ adsorption. Small, 2019, 15(8): e1804874.

[35] CAO X, XIA J, MENG X, et al. Stimuli-responsive DNA-gated nanoscale porous carbon derived from ZIF-8. Advanced Functional Materials, 2019, 29(34): 1902237.

[36] ZHANG F, LIU Y, LEI J, et al. Metal-organic-framework-derived carbon nanostructures for site-specific dual-modality photothermal/ photodynamic thrombus therapy. Advanced Science, 2019, 6(17): 1901378.

[37] ZHU D, CHENG K, WANG Y, et al. Nitrogen-doped porous 
carbons with nanofiber-like structure derived from poly (anilineco-p-phenylenediamine) for supercapacitors. Electrochimica Acta, 2017, 224: 17-24.

[38] XIA Y, MOKAYA R. Generalized and facile synthesis approach to $\mathrm{N}$-doped highly graphitic mesoporous carbon materials. Chemistry of Materials, 2005, 17(6): 1553-1560.

[39] PANICKAR R, SOBHAN C B, CHAKRAVORTI S. Chemical vapor deposition synthesis of carbon spheres: Effects of temperature and hydrogen. Vacuum, 2020, 172: 109108.

[40] XIA Y, MOKAYA R. synthesis of Ordered mesoporous carbon and nitrogen-doped carbor materials with graphitic pore walls viaa simple chemical vapor deposition method. Advanced Materials, 2004, 16(17): 1553-1558.

[41] LI W, LIU J, ZHAO D. Mesoporous materials for energy conversion and storage devices. Nature Reviews Materials, 2016, 1(6): 16023.

[42] KNOSSALLA J, JALALPOOR D, SCHüTH F. Hands-on guide to the synthesis of mesoporous hollow graphitic spheres and core-shell materials. Chemistry of Materials, 2017, 29(17): 2062-7072.

[43] WANGBO, ANG T P, BORGNA A. A rapid hard template method for the synthesis of $\mathrm{N}$-doped mesoporous carbon replicated from TUD-1. Microporous \& Mesoporous Materials, 2012, 158(8): 99-107.

[44] CHUENCHOM L, KRAEHNERT R, SMARSLY B M. Recent progress in soft-templating of porous carbon materials. Soft Matter, 2012, 8(42): 10801-10813.

[45] LIU J, WICKRAMARATNE N P, QIAO S Z, et al. Molecular-based design and emerging applications of nanoporous carbon spheres. Nat. Mater., 2015, 14(8): 763-774.

[46] PETKOVICH N D, STEIN A. Controlling macro- and mesostructures with hierarchical porosity through combined hard and soft templating. Chemical Society Reviews, 2013, 42(9): 3721-3739.

[47] WANG S, LV P, SHEN T, et al. Research progress in preparation of biomass-derived mesoporous carbon materials. Modern Chemical Industry, 2018, 38(10): 23-26.

[48] WANG T, WANG $H$. Research progress on porous carbon materials. Scientia Sinica Chimica, 2019, 49(5): 729-740.

[49] ZHUO R, ZHANG X, WANG X, et al. Research progress in functional metal-organic frameworks for tumor therapy. Acta Chimica Sinica, 2019, 77(11): 1156.

[50] WU H B, LOU X W D. Metal-organic frameworks and their derived materials for electrochemical energy storage and conversion: Promises and challenges. Science Advances, 2017, 3(12): eaap9252.

[51] WANG J, WANG Y, HU H, et al. From metal-organic frameworks to porous carbon materials: recent progress and prospects from energy and environmental perspectives. Nanoscale, 2020, 12(7): $4238-4268$.

[52] TANG J, SALUNKHE R R, LIU J, et al. Thermal conversion of core-shell metal-organic frameworks: a new method for selectively functionalized nanoporous hybrid carbon. Journal of the American Chemical Society, 2015, 137(4): 1572-1580.

[53] BORCHARDT L, ZHU Q-L, CASCO M E, et al. Toward a molecular design of porous carbon materials. Materials Today, 2017, 20(10): 592-610.

[54] HU M, REBOUL J, FURUKAWA S, et al. Direct carbonization of Al-based porous coordination polymer for synthesis of nanoporous carbon. Journal of the American Chemical Society, 2012, 134(6): 2864-2867.

[55] TORAD N L, HU M, KAMACHI Y, et al. Facile synthesis of nanoporous carbons with controlled particle sizes by direct carbonization of monodispersed ZIF-8 crystals. Chemical Communications (Cambridge, England), 2013, 49(25): 2521-2523.

[56] LIU H, YANG D, WANG X, et al. Metal-organic frameworkderived hollow carbon materials for electrochemical energy storage and oxygen reduction reaction. Chinese Journal of Inorganic Chemistry, 2019, 35(11): 1921-1933.

[57] LI J, GAO Y, HAN K, et al. High performance hierarchical porous carbon derived from distinctive plant tissue for supercapacitor. Scientific Reports, 2019, 9(1): 17270.

[58] DU J, YU Y, LV H, et al. Cauliflower-derived porous carbon without activation for electrochemical capacitor and $\mathrm{CO}_{2}$ capture applications. Journal of Nanoparticle Research, 2018, 20(1): 15-1-12.

[59] QIAN W, GUO J, YAN F, Design, synthesis and application of poly (ionic liquid)-based functional materials. Polym Bull., 2015, 10(10): 94-104.

[60] XU F, TANG Z, HUANG S, et al. Facile synthesis of ultrahigh-surface-area hollow carbon nanospheres for enhanced adsorption and energy storage. Nature Communications, 2015, 6: 7221.

[61] LI Z, WU D, HUANG X, et al. Fabrication of novel polymeric and carbonaceous nanoscale networks by the union of self-assembly and hypercrosslinking. Energy \& Environmental Science, 2014, 7(9): 3006.

[62] WU W, CHENG J, SHANG Y, Progress on preparation and application of porous carbon spheres. New chem. Mat., 2014, 42(12): 217-219.

[63] O.NYAMORI V, MHLANGA D S, COVILLE J N. The use of organometallic transition metal complexes in the synthesis of shaped carbon nanomaterials. Journal of Organometallic Chemistry, 2008, 693(13): 2205-2222.

[64] HO B N, PFEFFER C M, SINGH A T K. Update on nanotechnology-based drug delivery systems in cancer treatment. Anticancer Research, 2017, 37(11): 5975-5981.

[65] CHEN D, DOUGHERTY C A, ZHU K, et al. Theranostic applications of carbon nanomaterials in cancer: Focus on imaging and cargo delivery. Journal of Controlled Release, 2015, 210: 230-245.

[66] LI H, LIN Q, CHEN J, et al. Research progress of carbon nanomaterials in cancer drug delivery. Chemical Journal of Chinese Universities., 2019, 50(1): 100-106.

[67] ZHU S, XU G. Single-walled carbon nanohorns and their applications. Nanoscale, 2010, 2(12): 2538-2549.

[68] LAI L, BARNARD A S. Functionalized nanodiamonds for biological and medical applications. Journal of Nanoscience \& Nanotechnology, 2015, 15(2): 989-999.

[69] NARDECCHIA S, CARRIAZO D, FERRER M L, et al. Three dimensional macroporous architectures and aerogels built of carbon nanotubes and/or graphene: synthesis and applications. Chemical Society Reviews, 2013, 42(2): 794-830.

[70] CHENG L, WANG C, FENG L, et al. Functional nanomaterials for phototherapies of cancer. Chemical Reviews, 2014, 114(21): 10869-10939.

[71] KAPRI S, MAITI S, BHATTACHARYYA S. Lemon grass derived porous carbon nanospheres functionalized for controlled and targeted drug delivery. Carbon, 2016, 100: 223-235.

[72] KAPRI S, MAJEE R, BHATTACHARYYA S. Chemical modifications of porous carbon nanospheres obtained from ubiquitous precursors for targeted drug delivery and live cell imaging. Acs Sustainable Chemistry \& Engineering, 2018, 6(7): 8503-8514.

[73] XING Y, DAI L. Nanodiamonds for nanomedicine. Nanomedicine, 2009, 4(2): 207-218.

[74] LI C, MENG Y, WANG S, et al. Mesoporous carbon nanospheres featured fluorescent aptasensor for multiplediagnosis of cancer in vitro and in vivo. ACS Nano, 2015, 9(12): 12096-12103.

[75] LI C, QIAN M, WANG S, et al. Aptavalve-gated mesoporous carbon nanospheres image cellular mucin and provide on-demand targeted drug delivery. Theranostics, 2017, 7(13): 3319-3325.

[76] CHEN C, GENG J, PU F, et al. Polyvalent nucleic acid/mesoporous silica nanoparticle conjugates: dual stimuli-responsive vehicles for intracellular drug delivery. Angewandte Chemie, International Edition in English, 2011, 50(4): 882-886.

[77] CHOI Y, KIM S, CHOI M-H, et al. Highly biocompatible carbon nanodots for simultaneous bioimaging and targeted photodynamic therapy in vitro and in vivo. Advanced Functional Materials, 2014, 
24(37): 5781-5789.

[78] KONG Q, ZHANG L, LIU J, et al. Facile synthesis of hydrophilic multi-colour and upconversion photoluminescent mesoporous carbon nanoparticles for bioapplications. Chemical Communications (Cambridge, England), 2014, 50(99): 15772-15775.

[79] LI X, YAN Y, LIN Y, et al. Hollow mesoporous carbon as a near-infrared absorbing carrier compared with mesoporous carbon nanoparticles for chemo-photothermal therapy. Journal of Colloid and Interface Science, 2017, 494: 159-169.

[80] CHEN Y, XU P, WU M, et al. Colloidal RBC-shaped, hydrophilic, and hollow mesoporous carbon nanocapsules for highly efficient biomedical engineering. Advanced Materials, 2014, 26(25): 4294-4301.

[81] FANG Y, ZHENG G, YANG J, et al. Dual-pore mesoporous carbon@silica composite core-shell nanospheres for multidrug delivery. Angewandte Chemie, International Edition in English, 2014, 53(21): 5366-5370.

[82] DU X, ZHAO C, ZHOU M, et al. Hollow carbon nanospheres with tunable hierarchical pores for drug, gene, and photothermal synergistic treatment. Small, 2017, 13(6): 1602592.

[83] SINGHAL R, ORYNBAYEVA Z, KALYANA SUNDARAM R V, et al. Multifunctional carbon-nanotube cellular endoscopes. Nat. Nanotechnol., 2011, 6(1): 57-64.

[84] CHENG R, MENG F, DENG C, et al. Dual and multi-stimuli responsive polymeric nanoparticles for programmed site-specific drug delivery. Biomaterials, 2013, 34(14): 3647-3657.

[85] VEISEH O, GUNN J W, ZHANG M. Design and fabrication of magnetic nanoparticles for targeted drug delivery and imaging. Advanced Drug Delivery Reviews, 2010, 62(3): 284-304.

[86] CARDONE R A, CASAVOLA V, RESHKIN S J. The role of disturbed $\mathrm{pH}$ dynamics and the $\mathrm{Na}^{+} / \mathrm{H}^{+}$exchanger in metastasis. Nature Reviews: Cancer, 2005, 5(10): 786-795.

[87] HUANG X, WU S, DU X. Gated mesoporous carbon nanoparticles as drug delivery system for stimuli-responsive controlled release. Carbon, 2016, 101: 135-142.

[88] KESSENBROCK K, PLAKS V, WERB Z. Matrix metalloproteinases: regulators of the tumor microenvironment. Cell, 2010, 141(1): 52-67.

[89] SCHILling D, GARRIDO C, COMBS S E, et al. The Hsp70 inhibiting peptide aptamer A17 potentiates radiosensitization of tumor cells by Hsp90 inhibition. Cancer Letters, 2017, 390: 146-152.

[90] BRAYMAN M, THATHIAH A, CARSON D D. MUC1: a multifunctional cell surface component of reproductive tissue epithelia. Reproductive Biology and Endocrinology, 2004, 2: 4-1-9.

[91] SARKAR S, GULATI K, MISHRA A, et al. Protein nanocomposites: Special inferences to lysozyme based nanomaterials. International Journal of Biological Macromolecules, 2020, 151: 467-482.

[92] SCHAFER F Q, BUETTNER G R. Redox environment of the cell as viewed through the redox state of the glutathione disulfide/ glutathione couple. Free Radical Biology and Medicine, 2001, 30(11): 1191-1212.

[93] ZHOU L, DONG K, CHEN Z W, et al. Near-infrared absorbing mesoporous carbon nanoparticle as an intelligent drug carrier for dual-triggered synergistic cancer therapy. Carbon, 2015, 82: 479-488.

[94] BROADERS K E, GRANDHE S, FRECHET J M. A biocompatible oxidation-triggered carrier polymer with potential in therapeutics. Journal of the American Chemical Society, 2011, 133(4): 756-758.

[95] CHEN W, BALAKRISHNAN K, KUANG Y, et al. Reactive oxygen species (ROS) inducible DNA cross-linking agents and their effect on cancer cells and normal lymphocytes. Journal of Medicinal Chemistry, 2014, 57(11): 4498-4510.

[96] WANG L Z, LE L, KANG A, et al. Effects on the dispersion and cytotoxicity of ordered mesoporous carbon nanoparticles modified with PVP or PEG. Journal of Pharmacy Practice, 2016, 34(2):
$158-163$.

[97] GUPTA N, RAI D B, JANGID A K, et al. A Review of theranostics applications and toxicities of carbon nanomaterials. Current Drug Metabolism, 2019, 20(6): 506-532.

[98] XU G, LIU S, NIU H, et al. Functionalized mesoporous carbon nanoparticles for targeted chemo-photothermal therapy of cancer cells under near-infrared irradiation. RSC Advance, 2014, 4(64): 33986-33997.

[99] XUE C, LONGFEI T, TIANLONG L, et al. Micro-nanomaterials for tumor microwave hyperthermia: design, preparation, and application. Current Drug Delivery, 2017, 14: 307-322.

[100] SHAH B P, PASQUALE N, DE G, et al. Core-shell nanoparticlebased peptide therapeutics and combined hyperthermia for enhanced cancer cell apoptosis. ACS Nano, 2014, 8(9): 9379-9387.

[101] WANG Y, GU H. Core-shell-type magnetic mesoporous silica nanocomposites for bioimaging and therapeutic agent delivery. Advanced Materials, 2015, 27(3): 576-585.

[102] WU F, SUN B, CHU X, et al. Hyaluronic acid-modified porous carbon-coated $\mathrm{Fe}_{3} \mathrm{O}_{4}$ nanoparticles for magnetic resonance imagingguided photothermal/chemotherapy of tumors. Langmuir, 2019, 35(40): 13135-13144.

[103] HAI W, YULIANG Z, GUANGJUN N. Multifunctional nanoparticle systems for combined chemoand photothermal cancer therapy. Frontiers of Materials Science, 2014, 7: 118-128.

[104] ZHANG Y, HAN L, HU L-L, et al. Mesoporous carbon nanoparticles capped with polyacrylic acid as drug carrier for bi-trigger continuous drug release. Journal of Materials Chemistry B, 2016, 4(30): 5178-5184.

[105] ZHANG Y, CHANG Y-Q, HAN L, et al. Aptamer-anchored di-polymer shell-capped mesoporous carbon as a drug carrier for bi-trigger targeted drug delivery. Journal of Materials Chemistry B, 2017, 5(33): 6882-6889.

[106] YANG Z, WANG L, LIU Y, et al. ZnO capped flower-like porous carbon- $\mathrm{Fe}_{3} \mathrm{O}_{4}$ composite as carrier for bi-triggered drug delivery. Materials Science \& Engineering. C: Materials for Biological Applications, 2020, 107: 110256.

[107] CHEN L, ZHENG J, DU J, et al. Folic acid-conjugated magnetic ordered mesoporous carbon nanospheres for doxorubicin targeting delivery. Materials Science \& Engineering. C: Materials for Biological Applications, 2019, 104: 109939.

[108] CHEN L, ZHANG H, ZHENG J, et al. Thermo-sensitively and magnetically ordered mesoporous carbon nanospheres for targeted controlled drug release and hyperthermia application. Materials Science \& Engineering. C: Materials for Biological Applications, 2018, 84: 21-31.

[109] WANG H, CAO G, GAI Z, et al. Magnetic/NIR-responsive drug carrier, multicolor cell imaging, and enhanced photothermal therapy of gold capped magnetite-fluorescent carbon hybrid nanoparticles. Nanoscale, 2015, 7(17): 7885-7895.

[110] WU F, ZHANG M, LU H, et al. Triple stimuli-responsive magnetic Hollow porous carbon-based nanodrug delivery system for magnetic resonance imaging-guided synergistic photothermal/ chemotherapy of cancer. ACS Appl. Mater. Interfaces, 2018, 10(26): 21939-21949.

[111] ZHANG D X, ESSER L, VASANI R B, et al. Porous silicon nanomaterials: recent advances in surface engineering for controlled drug-delivery applications. Nanomedicine (Lond), 2019, 14(24): 3213-3230.

[112] ZHANG J, ZHANG J, LI W, et al. Degradable hollow Mesoporous silicon/carbon nanoparticles for photoacoustic imaging-guided highly effective chemo-thermal tumor therapy in vitro and in vivo. Theranostics, 2017, 7(12): 3007-3020.

[113] GUO W H, QI Y F, ZHANG Y Q, et al. Biocompatible caramelized carbonaceous nanospheres supported paramagnetic ultrathin manganese oxide nanosheets via self-sacrificing reduction as a MRI contrast agent for liver imaging. Carbon, 2016, 110: $321-329$. 